Old Dominion University

ODU Digital Commons

\title{
Modeling the Effects of Religious Belief and Affiliation on Prosociality
}

Luke Galen

Ross Gore

Old Dominion University, rgore@odu.edu

F. LeRon Shults

Follow this and additional works at: https://digitalcommons.odu.edu/vmasc_pubs

Part of the Computer Engineering Commons, and the Ethics in Religion Commons

\section{Original Publication Citation}

Galen, L., Gore, R., \& Shults, F. L. (2021). Modeling the effects of religious belief and affiliation on prosociality. Secularism and Nonreligion, 10, 1-21, Article 6. https://doi.org/10.5334/snr.128.

This Article is brought to you for free and open access by the Virginia Modeling, Analysis \& Simulation Center at ODU Digital Commons. It has been accepted for inclusion in VMASC Publications by an authorized administrator of ODU Digital Commons. For more information, please contact digitalcommons@odu.edu. 


\section{Modeling the Effects \\ of Religious Belief and \\ Affiliation on Prosociality}

\author{
LUKE GALEN
}

ROSS GORE (1)

\section{F. LERON SHULTS $\mathbb{C}$}

*Author affiliations can be found in the back matter of this article
NS SECULARISM \&

RN NONRELIGION

\section{] $\mathrm{u}[$ ubiquity press}

\begin{abstract}
To what extent do supernatural beliefs, group affiliation, and social interaction produce values and behaviors that benefit others, i.e., prosociality? Addressing this question involves multiple variables interacting within complex social networks that shape and constrain the beliefs and behaviors of individuals. We examine the relationships among some of these factors utilizing data from the World Values Survey to inform the construction of an Agent-Based Model. The latter was able to identify the conditions under which - and the mechanisms by which - the prosociality of simulated agents was increased or decreased within an "artificial society" designed to reflect real world parameters. The combined results indicated that prosociality was more related to agents' group affiliation and social networks than to their worldview beliefs. It also showed that prosociality changed as a function of agents' worldviews, group affiliation, and social network properties. Individuals with supernatural worldviews had higher levels of active prosociality, but this was primarily directed toward ingroup members. Naturalistic believers and the unaffiliated, on the other hand, tended to have higher levels of trust and tolerance. We describe the potential usefulness of such modeling techniques for addressing complex problems in the study of secularity and nonreligion.
\end{abstract}

\section{CORRESPONDING AUTHOR:}

\section{Luke Galen}

Grand Valley State University, US

galenl@gvsu.edu

\section{KEYWORDS:}

prosociality; altruism; religion; secularism; affiliation; supernatural belief

TO CITE THIS ARTICLE:

Galen, L, Gore, R and Shults, FL. 2021. Modeling the Effects of Religious Belief and Affiliation on Prosociality. Secularism and Nonreligion, 10: 6, pp. 1-21. DOI: https://doi.org/10.5334/ snr.128 
Determining the extent to which religion plays a role in the formation and maintenance of group behaviors within large-scale social systems is a complex problem and has generated a great deal of interest. For example, scholars have explored and debated the causal ordering in the relationships among religiosity, economic and cultural trends, and social development. Some secularization theories such as the existential security hypotheses postulate that the decline in influence of religious concepts and institutions within developed, stable societies can be explained by the fact that the former are no longer needed within the latter (Barber 2011; Norris \& Inglehart 2004). Interpreting the precise role of religion in society is difficult in part because supernatural beliefs are reciprocally related to other social effects in a complicated causal nexus.

Scholars also debate whether it was the emergence of religious beliefs in moral high gods that enabled and promoted the development of large-scale societies (Atkinson \& Bourrat 2011; Norenzayan 2016), or whether it was societal and economic developments that preceded and facilitated the appearance of largescale religions (Whitehouse et al. 2019). In other words, was it primarily belief in "Big Gods" that drove the rise of larger, more pluralistic societies or was it primarily factors related to the emergence of "Big Governments" that drove the rise of large religious institutions with beliefs in more powerful deities (or ultimate realities such as Dharma or Dao)? Such questions involve attending to the dynamic and multi-causal relationships among the component parts of complex systems (Shults, Wildman, Lane et al. 2018).

Here we focus on a related problem that has also engendered significant discussion among scholars, namely, the role of religion in promoting individuals' engagement in actions that benefit others, i.e., "prosocial" behaviors. This article explores four research questions that deal with the relationships among "active" and "passive" forms of prosociality, religious "belief", and religious "affiliation," which are answered using results from a statistical analysis of the World Values Survey (WVS) and from computational experiments in an Agent-Based Model (ABM) that were able to simulate the relevant longitudinal shifts in the WVS. First, we provide a survey of the literature and analysis of the current scientific debates over these issues.

\section{RELIGIOUS BELIEF AND PROSOCIALITY}

Due to the near-ubiquity of religion across historical time and geographical region, it is not surprising that the relationship to prosociality has usually been viewed from a religiously-normative perspective. Most people who are religious presume that religion motivates greater prosociality and morality (Pew Research Center 2014).
Conversely, it is commonly assumed that nonreligious individuals are less likely to behave prosocially because they do not endorse religious and spiritual beliefs, such as the idea that one's actions are monitored by supernatural agents (Gervais \& Norenzayan 2012). Consequently, sociological and anthropological theories have tended to focus on the presumed role that religious belief plays in the emergence of prosociality among individuals, groups, and societies. The "Big Gods" theory conceptualizes religion as a culturally-evolved set of beliefs and practices that feature moralizing, supernatural agents that monitor prosocial behavior and enforce social cohesion (Atkinson \& Bourrat 2011; Johnson 2005; Norenzayan 2016; Purzycki et al. 2016). Such theories suggest a specific historical role for shared belief in powerful and socially-interested deities who monitor human interactions, which ex hypothesi leads to a greater willingness to treat strangers fairly in exchanges and facilitates the emergence of cooperative norms (Henrich et al. 2010).

But are socially-shared religious concepts such as supernatural monitoring necessary for the emergence of cooperative group norms? Or can nonreligious and secular social groups generate prosociality without supernatural beliefs? Theories postulating that a prevalent belief in God is linked to more functional societies are contradicted by findings that countries with the greatest proportion of nonbelievers - "societies without Gods" - tend to have higher, not lower, levels of prosociality (Zuckerman 2008). Many Big Gods proponents acknowledge that although religion initially provided the conditions for the establishment of cooperative norms, today these functions are often performed by alternative secular institutions. In some modern societies, competent governance and institutionalized social welfare programs have now largely replaced the influence of religious concepts and institutions (Guo, Liu, \& Tian 2018). In the words of Big Gods theorist Ara Norenzayan, secular societies have "...climbed the ladder of prosocial religion and then kicked it away" (Norenzayan 2016: 18). Unfortunately, we cannot "rewind the tape" of history while systematically changing parameters in order to determine how (or whether) prosocial norms would have developed differently in the absence of religious concepts.

\section{COMPLEXITY OF PROSOCIALITY}

Another problem complicating the identification of the functions of religion in motivating prosociality is the complexity (and varying manifestations) of the latter. Which aspects of prosocial behavior are most relevant to optimal social functioning? Cooperation with unfamiliar people such as outgroup members and strangers (rather than ingroup members such as kin and neighbors) seems to be a necessary condition for a successful large-scale 
society. This suggests that a fundamental property of broader prosocial orientation is the belief that most strangers can be trusted. Indeed, generalized trust is strongest in the most functional societies (Balliet \& Van Lange 2013). Because groups typically become more heterogeneous as they grow, another component of cooperation is tolerance of diverse individuals, which is also associated with social groups that are more affluent and functional (Florida, Mellander \& Stolarick 2008). Both trust and tolerance can be thought of as "passive" prosocial values in the sense that they require relatively little proactive behavior. By contrast, some other forms of prosociality require more initiative by way of sharing time or resources in assisting others or promoting the general welfare of the community. One manifestation of "active" prosociality is civic engagement in the form of volunteering (Putnam 2000; Wang \& Graddy 2008).

Does religiosity itself contribute to these various manifestations of prosociality? In the case of active volunteering, establishing a clear, unambiguous causal link with religious belief has been problematic. Although some studies have suggested that religiosity promotes volunteering (Einolf 2011; Petrovic, Chapman, \& Schofield 2018), the literature is marked by contradictory findings. Some studies have found that religious attendance is associated with increased volunteering (Ruiter \& De Graaf 2006) while others have suggested that this effect may be limited to certain countries (Van der Meer et al. 2010). Even more confusingly, some studies have found a negative relationship between national-level religiosity and volunteering (Prouteau \& Sardinha 2015). These discrepant results exemplify the general difficulty of attempting to isolate the effect of religious beliefs in social functioning.

\section{RELIGIOUS OR SECULAR EFFECTS?}

It has frequently been assumed that any behavioral differences between religious and nonreligious individuals are attributable to their beliefs. However, such individuals differ in ways unrelated to belief. Religious believers tend to be affiliated with religious institutions (e.g., membership in a church, temple, or mosque) and more regularly attend group-related social events (e.g., services, meetings, organized activities). Religious groups have been found to be particularly rich in social networking, social support, and the encouragement of group cohesion via structured activities (Beyerlein \& Hipp 2006), factors which collectively constitute social capital (Putnam \& Campbell 2010). Consequently, when we compare the prosociality of religious believers and nonbelievers, we risk potentially confounding differences in worldviews with affiliation-related factors (Galen \& Kloet 2011a; Galen, Sharp \& McNulty 2015).

Social dynamics have a major influence on prosocial actions. For instance, studies attempting to separate worldview beliefs from social affiliations have found that a range of prosocial behaviors, including volunteering and charitable donations, are more closely related to active religious group participation (e.g., attending services) than to religious identification itself (Burge 2019; Low et al. 2007). The factors that contribute most to greater levels of civic participation and volunteering involve access to social contacts and networking influences found in religious groups (Becker \& Dhingra 2001; Lewis, MacGregor \& Putnam 2013; Monsma 2007). Studies that hold constant social factors such as group attendance have found that religious beliefs themselves are unrelated, or even negatively related, to generalized trust and volunteering (Burge 2019; Loveland, Capella \& Maisonet 2017; Petrovic, et al. 2018; Putnam \& Campbell 2010). Nonreligious individuals also engage in more volunteering if they are socially linked to active members of religious congregations (Lim \& MacGregor 2012), which further weakens the claim that religious beliefs are the primary driver of prosociality.

Regardless of their religious or secular ideology, social groups can produce prosocial outcomes when they include opportunities for structured charitable activity and requests for donations of time or money (Becker \& Dhingra 2001; Merino 2013). In fact, secular and humanistic-themed groups featuring social networking and positive norms promote prosociality in a manner equivalent to religious congregations (Galen, Sharp \& McNulty 2015). Some nonreligious groups, such as "Sunday Assembly," attempt to incorporate churchlike elements such as music, uplifting messages, and participation in small group activities, which increase secular participants' well-being over time (Price \& Launay 2018). Such findings suggest that supernatural beliefs do not constitute the core prosocial element of group participation. Unfortunately, one consequence of conflating religious beliefs with group affiliation is that discussions of factors distinguishing religious believers from nonbelievers tend to focus more on differences in supernatural beliefs rather than on social and grouprelated factors.

\section{SCOPE OF PROSOCIALITY}

The patterns of prosocial values and behaviors are not simply manifested indiscriminately but are often contingent upon the identity of the intended beneficiaries. Parochial (restricted, or tribal) prosociality refers to values (e.g., trust) or behaviors (e.g., charitable donations) that apply selectively only to those within a circumscribed radius, such as kin, fellow co-religionists, or members of a specific cultural ingroup (Saroglou 2006). By contrast, universal prosociality refers to prosocial behaviors that are performed for outgroup as well as ingroup members. There is evidence that religious 
factors lead to a tribalization of prosociality, channeling it towards ingroup members and constraining the radius of concern (Putnam \& Campbell 2010). For instance, studies have found that religious belief is associated with volunteering for beneficiaries that affirm religious values but not with volunteering for secular causes (Lam 2002). By contrast, nonreligious individuals have a more universal or extended pattern of prosociality (McKay \& Whitehouse 2015; Shariff, Piazza \& Kramer 2014). Those who are unaffiliated volunteer at equivalent or greater rates than the religiously affiliated when the type of volunteering is generalized and not via a religious organization (Cragun 2013; Emerson \& Sikkink 2006). As a result, religious effects on volunteering are weak to nonexistent in general community contexts when the recipient is not identifiably religious (Low et al. 2007; Monsma 2007; Wang \& Graddy 2008). We can therefore generally characterize the role of religiosity as having more of an effect on where and why people volunteer rather than on whether or not they volunteer (Borgonovi 2008; Galen, Sharp \& McNulty 2015).

To understand the relative scope (parochial or universal) of the passive prosocial values mentioned above (trust and tolerance), it is important to note the way in which the expression of prosociality is intertwined with the characteristics of individuals' social relationships and networks. Social affiliations and groups vary in ways that affect the extent to which members trust those within, as opposed to those outside, the group. Social interaction and contacts made within a homogeneous group ("bonding" social capital) are distinct from heterogeneous contacts with others in different groups ("bridging" social capital). Bridging capital is associated with a more universal form of prosociality, manifested in generalized trust and communal volunteering. By contrast, tribal or bonding prosociality is characterized by lower trust and intolerance of heterogeneity. These distinctions are directly relevant to religiously-affiliated groups because while they have strong within-group network ties they tend to have weaker outgroup ties. This effect is related to the fact that religious groups typically have more homogeneous and homophilous social networks relative to the networks of nonreligious and unaffiliated individuals (Cheadle \& Schwadel 2012), as well as the fact that nonreligious individuals tend to show more generalized trust (Loveland, Capella \& Maisonet 2017; Welch, Sikkink, \& Loveland 2007). Thus, the same dynamics at work in the promotion of social bonding and capital within religious groups are also linked to ingroup homophily and to intolerance of those outside the group.

\section{CHANGES IN BELIEF AND AFFILIATION}

The dynamic nature of religious beliefs and group affiliation also makes it difficult to determine their influence on altruistic behavior. Do changes in belief and affiliation over time affect the emergence and/or expression of prosociality? For example, if an individual's prosocial pattern is formed within a religious group context as a function of social network influences, would this pattern be altered if that person's religious beliefs changed? Answering such questions requires a more general understanding of what factors precipitate decreased religious belief (sometimes referred to as apostasy). The factors most frequently examined in the psychological literature in this regard have tended to be individual differences in personality and cognition. For example, traits such as openness to experience and authoritarianism (involving the tendency to welcome diversity in the case of the former, and oppose it in the case of the latter) have been found to predict decreased versus sustained or increased religiosity, respectively (Galen \& Kloet 2011a; Wink, Dillon \& Prettyman 2007). Those raised in nonreligious environments who subsequently convert to religiosity in adulthood self-report higher levels of authoritarianism. This contrasts with those whose religiosity has decreased over time, who more often report having tolerant and nonauthoritarian personalities (Altemeyer \& Hunsberger 1997). It is notable that trait authoritarianism at its core involves an emphasis on strong ingroup loyalty combined with outgroup suspicion and intolerance.

Although these factors have been reliably linked to retrospective reports of religious change, there are still questions regarding whether these traits have a preexisting influence that triggers religious change over time. Do such traits predispose individuals to a trajectory of decreased religiosity, or do these traits develop as a consequence of decreased religiosity? Studies that are most informative in this regard are longitudinal in design. Even these results are not entirely consistent. For example, one study found that those with higher levels of the prosocial personality trait agreeableness earlier in life tend to become more religious over time (McCullough et al. 2005). However, another study found the same association but in the reverse causal order - higher levels of religious values earlier in youth predicted later increases in agreeableness (Huuskes, Ciarrochi \& Heaven 2013).

As outlined above, given the importance of ingroup relationships in determining the quality and degree of prosociality, interpersonal influences are arguably the most important factors in determining religious change. The presence of fellow believers serves a protective function in maintaining and defending worldviews from potential threats. Without social support, the cognitive dissonance resulting from exposure to disconfirmatory information can lead to doubts or wholesale worldview rejection (Festinger, Reicken \& Schachter 1956). One method by which groups characterized as sharing a homogeneous worldview typically maintain cohesion 
is limiting members' contacts with outsiders with worldviews (Galanter 1980). In addition to factors originating externally to the group such as contact with those who do not share group values, withingroup factors may also influence belief change, albeit not always in a belief-affirming direction. For instance, negative interpersonal interactions within the believer's group (e.g., a perceived failure of others to live up to ideals) can cause individuals to doubt previouslyaccepted, normative group beliefs (Hunsberger et al. 1996; Krause \& Ellison 2009). Therefore, not only is the heterogeneity of the group's social network predictive of belief change, but so are the quality and valence of relationships with others in the network.

In the case of religious belief change, social influences within religiously-normative cultures have typically tended to function more in the direction of increasing religious affiliation. By contrast, the process of disaffiliation or rejection of beliefs tends to be a more solitary one. In one study, nonreligious college students who were raised religiously described an individualistic journey of shedding their beliefs that was self-initiated through their own search for the truth. The same study found that converts to religion were socially assisted via contacts with religious friends and significant others (Altemeyer \& Hunsberger 1997). Relatively small differences in religious belief earlier in life tend to become amplified or polarized as individuals self-sort into like-minded social groups (Ozorak 1989). A person who has difficulty with a religious upbringing or church may elect to attend a secular university or socialize within peer networks that include nonreligious individuals, which can further erode religious beliefs. This also illustrates the difficulty in studying changes in prosociality as a function of major variables such as supernatural belief, group affiliation, and social network properties - all these parameters could potentially interact in a multi-causal way.

\section{USE OF COMPUTER MODELING}

One tool that is increasingly being used to examine such problems involving multi-causality is agent-based modeling ( $\mathrm{ABM}$ ). By using this method, a phenomenon can be modeled as a collection of autonomous decision-making entities (agents). Each simulated agent individually assesses its situation and makes decisions based on a set of rules, executing various behaviors and interactions within an artificial society. Repeated interactions among agents are a feature of $A B M$. This feature highlights dynamics related to the phenomenon out of the reach of more static analytical methods (Axelrod 1997; Epstein \& Axtell 1996). A simple ABM can exhibit complex behavior patterns and provide valuable information about the dynamics of the emulated phenomenon (Reynolds 1987). In addition, agents may be capable of evolving, allowing unanticipated behaviors to emerge. ABM lends advantages in studying social scientific phenomena such as those in which individuals' behavior may be contingent on the behaviors of others, including changes that occur over time (Madsen et al. 2019).

This helps to explain why this methodology is increasingly being applied to issues in the scientific study of religion and nonreligion (Iannaccone 2007; Makowsky 2019; Gore et al. 2018; Lane, Shults \& McCauley, 2019; Shults, 2018; Shults, Gore, Wildman et al. 2018; Shults, Lane, Diallo et al. 2018) In one example of such an application, Lane (2018) used an ABM to study cooperation in the prisoner's dilemma game. Agents' belief in supernatural punishment (i.e., belief that defecting in interactions with other agents will be punished) was manipulated. The results did not support the theory that belief in supernatural punishment causes greater cooperation in a population.

\section{CURRENT STUDY}

In an attempt to address questions regarding how supernatural beliefs, group affiliation, and social network properties all relate to the emergence of prosociality, we developed an Agent-Based Prosociality Model, based on real world data from the World Values Survey (WVS). This involved: (1) the operationalization of prosociality with respect to supernatural beliefs, group affiliation, and social networks in multiples waves of data collection from the World Values Survey and previously established ABM; (2) statistical analysis of the WVS data set using the operationalization to identify statistically significant differences; (3) reproducing the same statistically significant differences within an extended ABM and (4) analyzing the $A B M$ to produce an explanation of the causes of statistically significant differences observed in the WVS. Thus, for each of the research questions discussed below, we first report our analysis of the realworld WVS findings followed by the ABM findings that help to reveal which dynamics in the model produce the observed outcomes.

Our main variables of interest include the worldviews of individuals or agents (i.e., supernatural or naturalistic), affiliation status (members of a club or unaffiliated), and types of prosociality (i.e., active and passive). It was hypothesized that individuals who had supernatural worldviews and who were affiliated with supernatural worldview groups would display greater levels of prosociality relative to those with naturalistic worldviews or those unaffiliated with shared-worldview groups. However, it was also predicted that the type of prosociality performed by groups with a shared religious worldview would be largely confined to the group, as opposed to universalistic in nature. Whereas the first 
set of the modeling studies (research questions 1 and 2) examined prosocial behaviors as a function of fixed or static worldviews and affiliation, the second set (research questions 3 and 4) utilized longitudinal data to incorporate changes in worldview and affiliation over time. This was designed to untangle the causal relationships between individuals' levels of trust and tolerance and their social affiliation and interactions. Specifically, these studies attempted to determine whether prosociality preceded changes in belief or affiliation or were largely a result of such change.

\section{METHODS \\ PROCEDURE}

We analyzed the longitudinal data and survey data from two waves (Wave 2; 1990-1994 and Wave 4: 1999-2004) of the WVS. The corresponding Agent Based Model (ABM) was created using the Artificial Society Analytics Platform (ASAP), which provides an artificial society in which agents have simulated experiences such as growing up, moving into the work force, marrying, having children, and dying (Shults et al. 2020). In the simulations described below, agents were programmed to have certain worldviews, affiliations, and other values that could change over time as a result of interactions with other agents, known as "alters." The degree and direction of changes in agents' beliefs depended upon such factors as consistency with the worldview of the encountered alters (for details, see online supplemental material).

\section{MEASURES}

\section{WVS Worldview}

Using the WVS data, we categorized individuals as having a supernatural worldview if they reported belief in God, heaven, or hell. If they denied belief in all three, then their worldview was categorized as naturalistic. Those with mixed patterns (i.e., answering any of the three items differently or “Don't Know”) were excluded from analysis.

\section{ABM Worldview}

In the ABM simulation, agents were deemed to have a supernatural (i.e. belief in God), or naturalist (no belief in God) worldview, depending upon whether their value was above or below 0.5 , respectively.

\section{WVS Affiliation}

Using the WVS data, individuals were deemed to be affiliated with a shared-worldview group if they reported a supernatural worldview and attended religious services at least once a month. We labelled these groups "worldview clubs." The analysis was limited to supernatural worldview club affiliation because of a lack of cross-cultural surveys that included data on group affiliation with naturalist worldview clubs and active prosociality (i.e., volunteerism).

\section{ABM Affiliation}

In the $A B M$ simulation, agents with a supernatural worldview could also be affiliated with a supernatural worldview club, which had a designated leader called an exemplar. Agents were considered affiliated if they had a supernatural worldview, had a neutral or positive interaction with the exemplar agent, observed the exemplar agent act in a manner consistent with a supernatural worldview, or had an outgroup suspicion value (defined below) above a specified threshold. Conversely, agents could disaffiliate if their worldview was no longer supernatural, if they had negative interactions with the exemplar agent, if the exemplar agent acted inconsistently with their worldview, or if the agent's outgroup suspicion was below the threshold.

\section{ABM Social Network Properties}

Within the agent-based simulation, agents interacted with different types of social networks including the: (1) agent's family, (2) agent's online social network, (3) agent's offline social network, (4) agent's neighbors (neighborhood), (5) agent's co-workers (job), if the agent had a job, and (6) other members affiliated with the same supernatural worldview club, if the agent was affiliated with a supernatural worldview club. Family networks consisted of parents and siblings; neighborhood networks were all agents in the same neighborhood as the given agent; online networks were agents selected at random from the entire population upon agent inception; work networks were all agents working at the same job location. Offline social networks were stochastic with the probability of being someone else's alter agent inversely proportional to the spatial distance between the given agent and the alter. Thus, networks varied in homophily, ranging from relatively narrow and homogeneous (e.g., restricted to family, worldview club-affiliated) to relatively broad and heterogeneous (e.g., outside of affiliation).

A target agent's worldview could change by interacting with alter agents. Worldview beliefs were either strengthened or diminished by observing actions of the alter agent as a function of whether: 1) the target agent shared the alter agent's worldview; and 2) the actions of the alter agent were consistent versus inconsistent with the target agent's worldview. If the target agent observed a consistent action by an alter agent with a shared worldview, then the target agent's worldview was strengthened. However, if an alter agent of similar worldview was observed performing an inconsistent action, then the target agent was conflicted and their worldview moved in the opposite direction. This process is shown in Figure 1.

\section{WVS Active Prosociality}

Within the context of the World Values Survey, we defined active prosociality as voluntary acts associated with one of the types of organizations listed in Table 1. We 


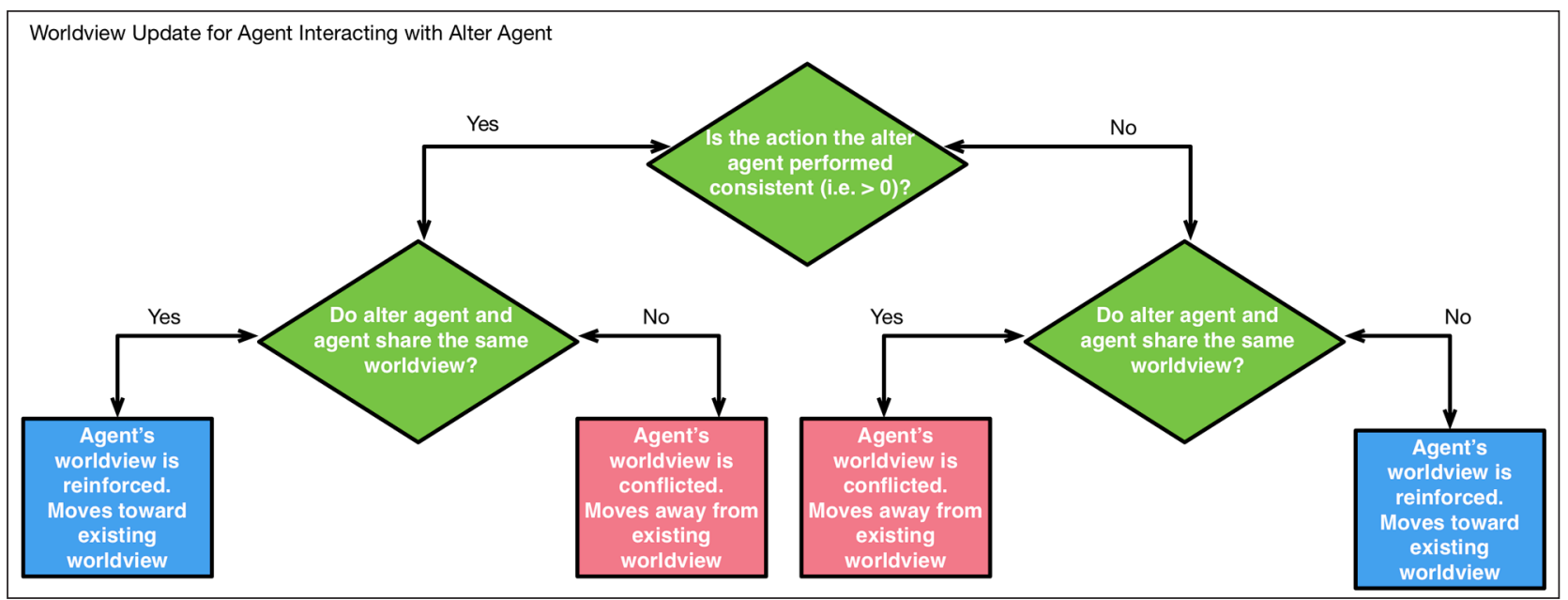

Figure 1 The Process by Which an Agent Updates Their Worldview After Interacting With an Alter Agent.

\begin{tabular}{|c|c|c|c|}
\hline ACTION TYPE & \multicolumn{3}{|c|}{ ORGANIZATION (ORG.) ASSOCIATED WITH THE VOLUNTARY ACTION } \\
\hline Tribal & Church & & \\
\hline Ideological & $\begin{array}{l}\text { Labor Union } \\
\text { Professional Org. }\end{array}$ & Political Org. & Local Community Org. \\
\hline Universal & $\begin{array}{l}\text { Social Welfare Org. } \\
\text { Youth Work Org. Sports/Rec. Org. }\end{array}$ & $\begin{array}{l}\text { Arts/Music Org. } \\
\text { Women's Group Peace } \\
\text { Movement Org. }\end{array}$ & $\begin{array}{l}3^{\text {rd }} \text { World Human Rights Org. } \\
\text { Conservation, Environment or Animal } \\
\text { Health Org. }\end{array}$ \\
\hline
\end{tabular}

Table 1 Operationalization of Prosocial Action Types.

categorized volunteering for each type of organization as tribal, ideological, or universal. Tribal prosocial actions were those performed directly for the worldview club to which an individual was affiliated. Ideological prosocial actions were performed without direct consideration for an individual's worldview but taken on behalf of the individual to help themselves and others like them. Universal prosocial actions were performed without direct consideration for one's worldview or one's self.

\section{ABM Active Prosociality}

Within the simulation, agents had the opportunity to engage in prosocial actions based on a two-step process. First, the different types of prosocial action opportunities (Table 1) were generated based on the agent's inclusion in different social networks.

Specifically, to be given a tribal prosocial action opportunity the agent must have been in a supernatural worldview club and drawn a random number between 0 and 1 from a uniform distribution that went above a specified threshold. For ideological and universal prosocial actions, the simulation generated opportunities based on the involvement in all social networks. This included whether or not the agent had a job, was married, and was also dependent upon the relative sizes of their online and offline social network. In each of these cases a stochastic process determined whether an ideological or universal prosocial action opportunity was generated. However, this likelihood was increased based on the number and size of the agent's online and offline social networks. This process is shown in Figure 2.

In order to take a prosocial action an agent must have had an opportunity generated and must have accepted that opportunity. Acceptance was based on: (1) their level of extraversion and (2) whether the previous opportunity was accepted. This process is shown in Figure 3.

\section{WVS Passive Prosociality}

Within the context of the WVS, passive prosociality was defined in two ways: self-reported trust and tolerance of others. We based the trust dimension of passive prosociality on an individual's affirmative response to the WVS question: "Generally speaking, would you say that most people can be trusted" (versus "you need to be very careful in dealing with people?"). Tolerance was defined as a negative response to the question: "Would you prefer to not have these people as neighbors: (1) people of a different race and (2) immigrants/foreign workers?"

\section{ABM passive prosociality}

Within the agent-based simulation, passive prosociality was also based on trust and tolerance. Trust was defined as a normalized measure of the total size of an agent's social networks. For example, an agent with a total network size greater than $90 \%$ of all the other agents' network size would have a trust level of 0.9 . 


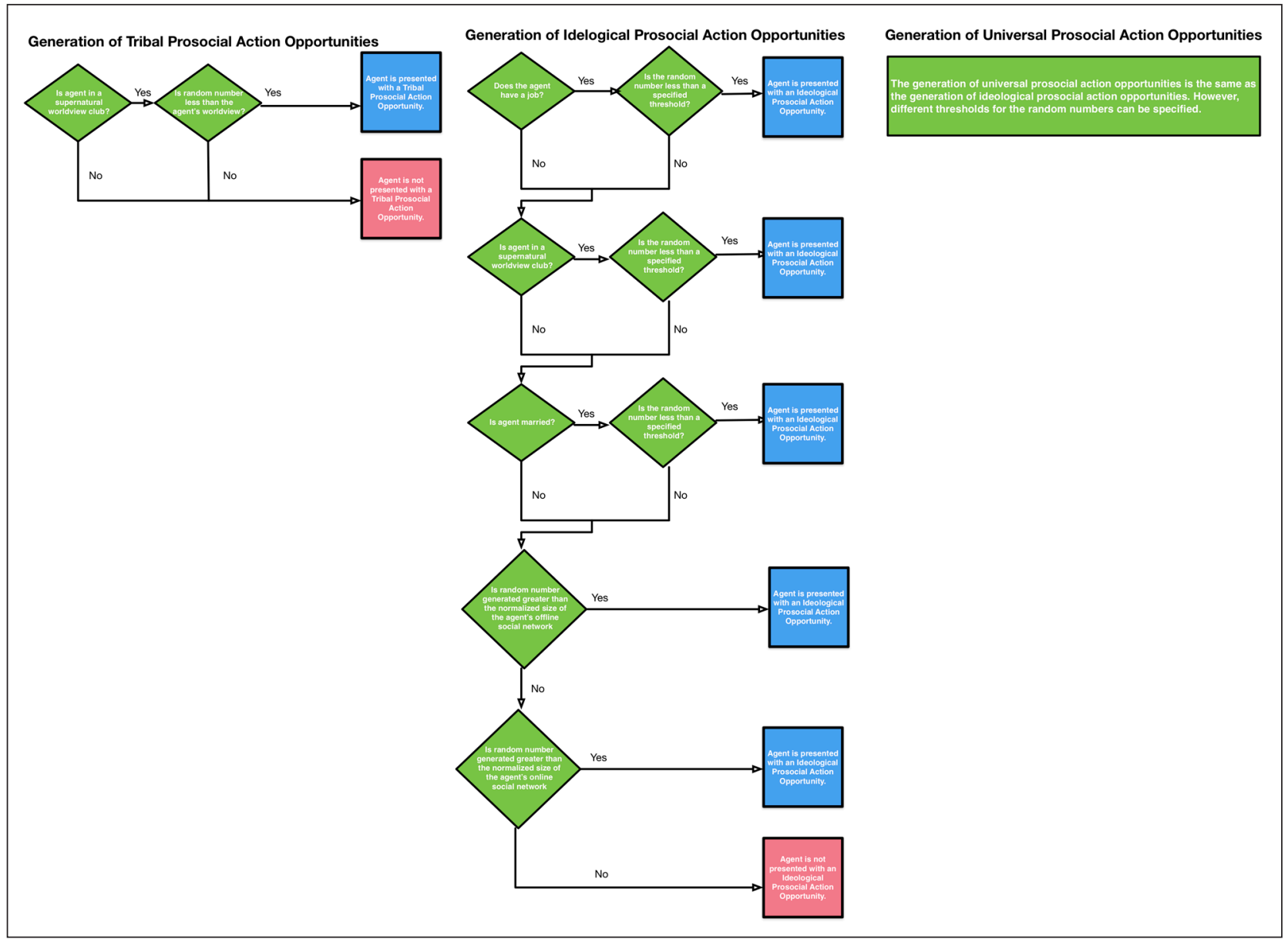

Figure 2 The Process by Which Each Type of Prosocial Action Opportunity is Generated for an Agent.

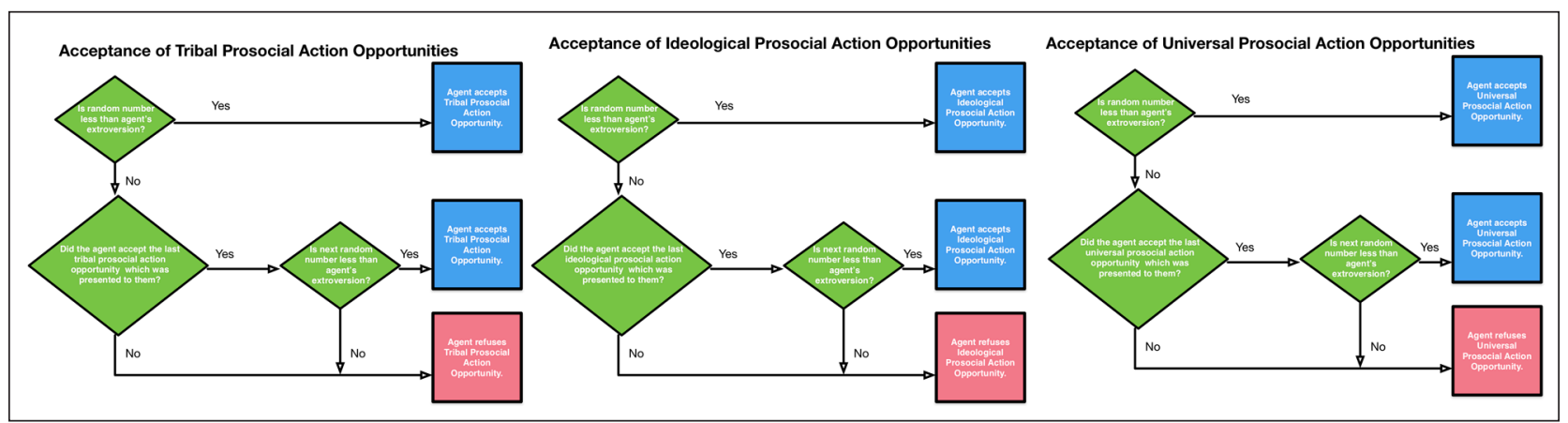

Figure 3 The Process by Which an Agent Accepts or Refuses Prosocial Action Opportunities.

Similarly, an agent whose total social network size was at the median value of that of other agents would have a level of 0.5 .

The variable of tolerance was based on two other variables: the designation of agents as members of a majority or a minority group, and their (inverse) outgroup suspicion value. If an agent was designated as being in the majority group, outgroup suspicion reflected the degree of suspicion that agent has towards the minority group. If the agent was in the minority group, outgroup suspicion reflected the degree of suspicion that agent has towards the majority group. Interactions with other agents could be categorized as positive, negative, or neutral, which could increase or decrease the agent's outgroup suspicion. The value of tolerance was inversely proportional to an agent's outgroup suspicion value. In majority-minority and minority-majority interactions, if the random number drawn by an agent from a uniform distribution exceeded their outgroup suspicion value then the agent was designated as having a positive interaction, increasing their tolerance. If the random number was equal or below the agent's outgroup suspicion value, then the agent was designated as having a negative interaction, decreasing tolerance. Majority-majority and minority-minority interactions were categorized as neutral. Thus, higher outgroup suspicion reflected the likelihood that an agent would have a negative 
interaction with the other group. These dynamics are shown in Figure 4.

In the simulation, an agent could remove an alter agent from its online or offline social network, which were reviewed after each round of interactions. For each alter agent in the online or offline social network the agent checked whether a specified number of the last interactions were neutral or positive. If positive, the alter agent was retained in the network; if negative, the alter agent was removed. These dynamics are shown in Figure 5.

\section{ABM Changes in Affiliation with a Worldview Club} In order to affiliate with a supernatural worldview club an agent must: (1) have a supernatural worldview, (2) not be in another supernatural worldview club, (3) be connected to the club's exemplar agent in one of their social networks, (4) have had their last interaction with the exemplar agent be positive or neutral, and either ( $5 a$ ) have last observed the exemplar agent act in a manner consistent with a supernatural worldview or (5b) have tolerance below a specified threshold. An agent could leave the supernatural worldview club if any of the following were true: (1) their worldview was no longer supernatural, (2) a certain number of the last interactions with the exemplar agent were not positive or neutral, or (3) the agent had not observed the exemplar agent act in a manner consistent with the exemplar's worldview in a certain number of the last interactions, and the agent's tolerance was above the specified threshold. These processes are shown in Figure 6.

\section{RESULTS}

An overview of the questions and results are shown in Table 2. In what follows we review each question in detail first with the WVS data, followed by a presentation of the $A B M$ results and an explanation of the modeling dynamic that produced those results.

\section{RESEARCH QUESTION \#1: IS PROSOCIALITY BASED ON AFFILIATION WITH A SUPERNATURAL WORLDVIEW CLUB?}

\section{Active Prosociality}

Recall that within the WVS data we defined active prosociality as voluntary acts for organizations. Individuals affiliated with a supernatural worldview club

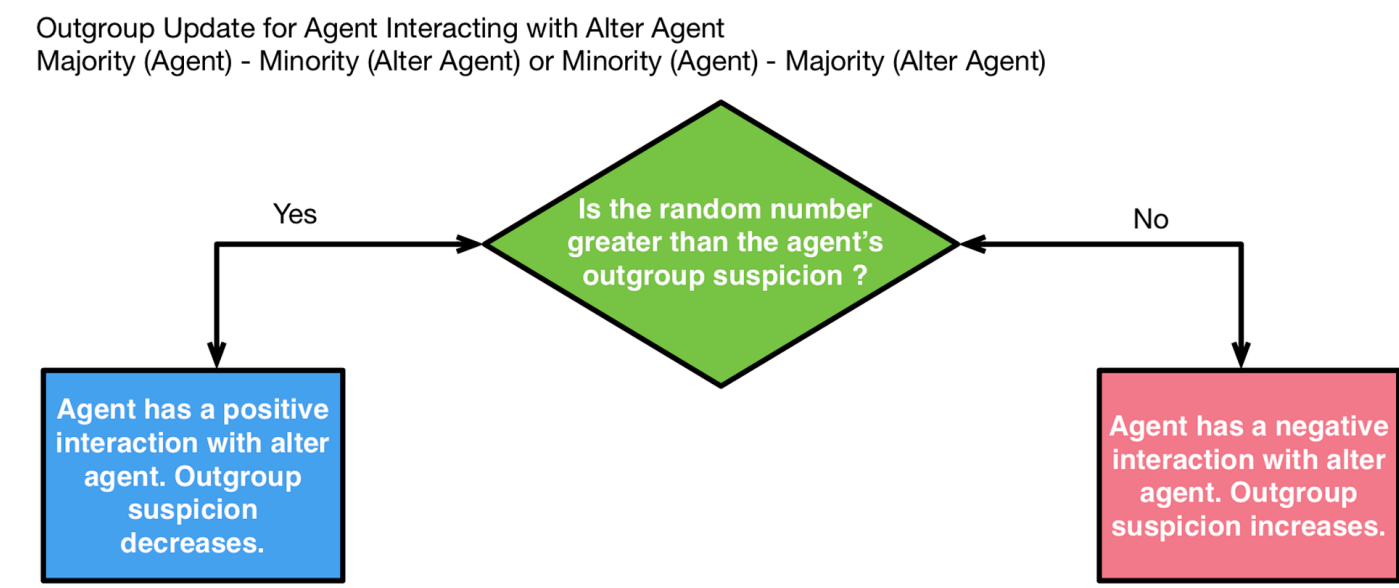

Outgroup Update for Agent Interacting with Alter Agent Majority (Agent) - Majority (Alter Agent) or Minority (Agent) - Minority (Alter Agent)

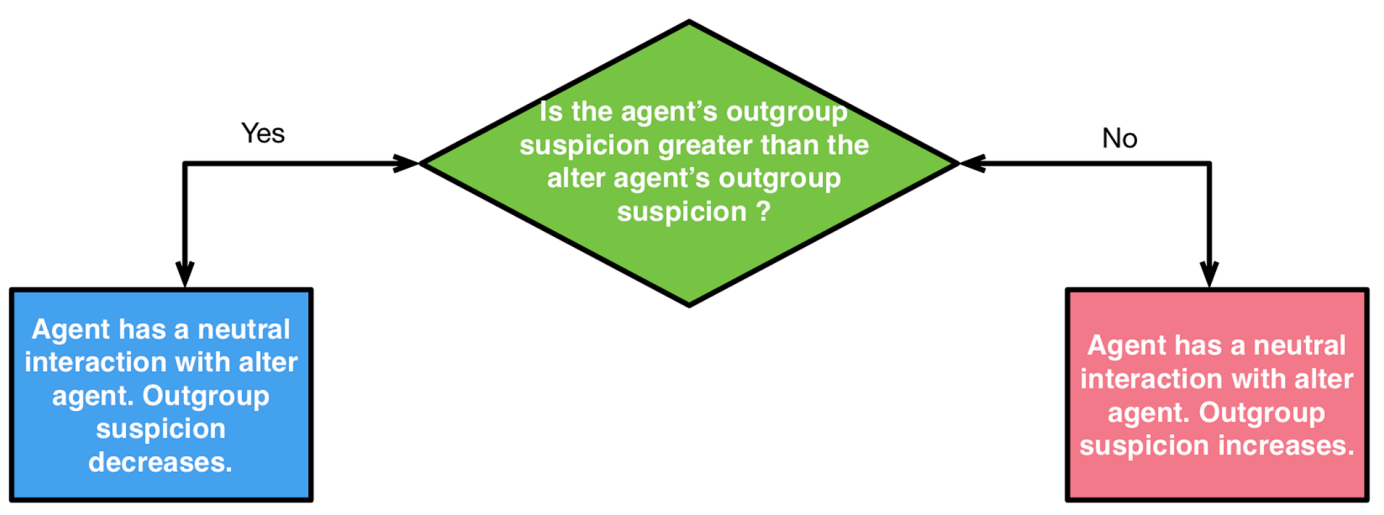

Figure 4 The Process by Which an Agent Updates its Outgroup Suspicion (Inverse Tolerance). 


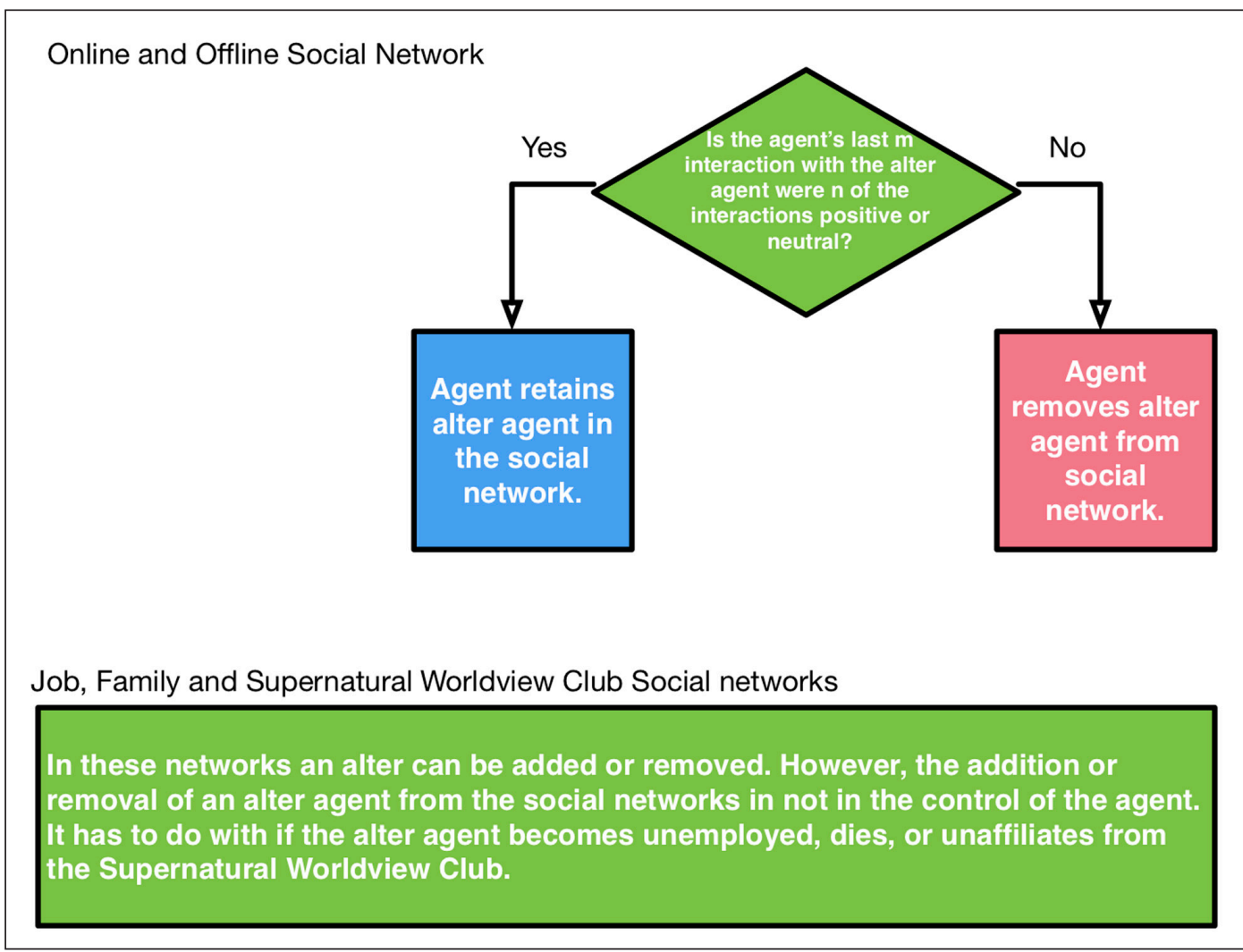

Figure 5 The Process by Which an Agent Removes Individuals From its Social Networks.

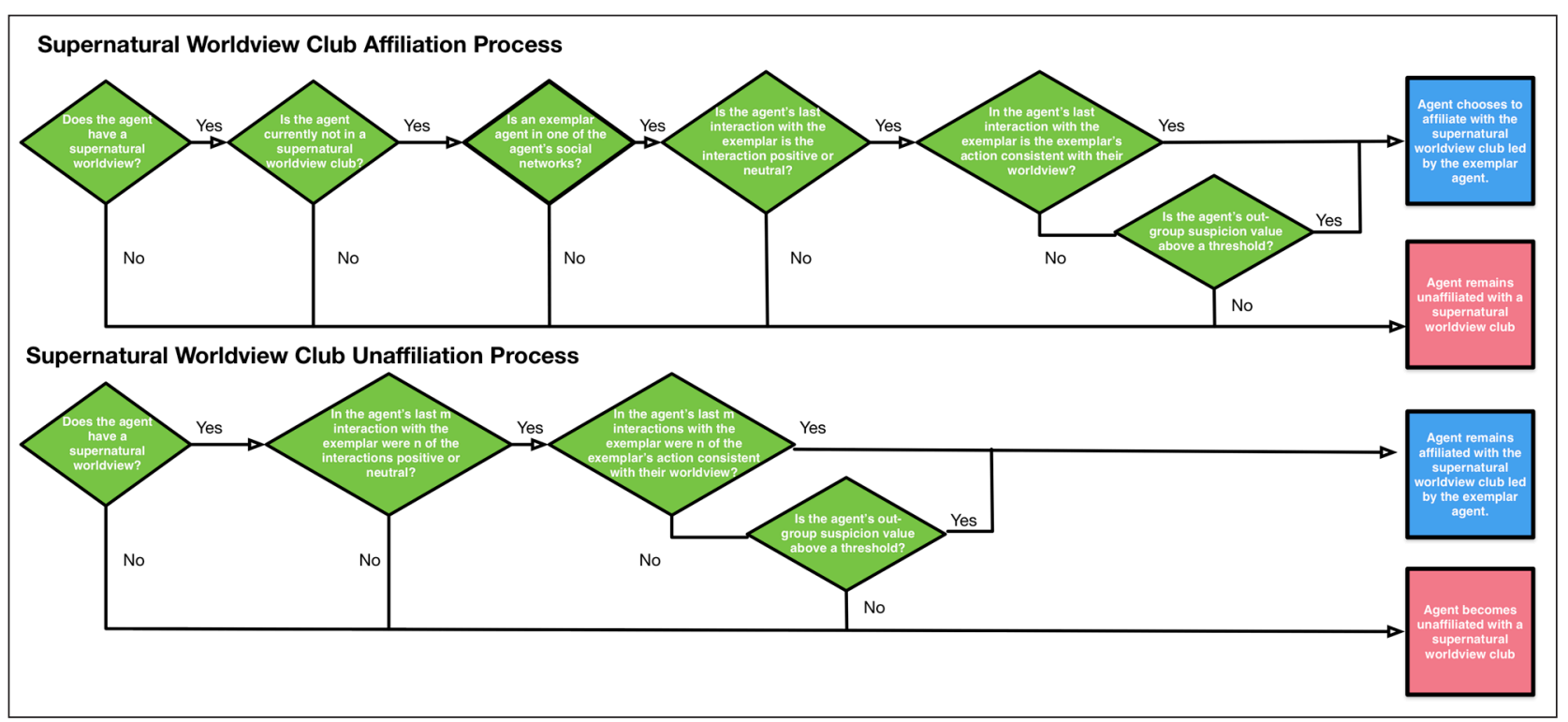

Figure 6 The Process by Which an Agent Affiliates or Disaffiliates With a Supernatural Worldview Club.

were significantly more likely $(M=42.7 \%, S D=0.49)$ than individuals not affiliated with a worldview club $(M=$ $22.2 \%, S D=0.42)$ to be actively prosocial $t(14518)=28.1$, $p<0.01$. The exclusion of tribal prosociality from the analysis reduced the average level of active prosociality by individuals in a supernatural worldview club $(M=$ $30.4 \%, S D=0.46)$. However, it was still significantly higher than the active prosociality of the unaffiliated ( $M$ $=22.2 \%, S D=0.42), t(15017)=11.8, p<0.01$.

Likewise, within the agent-based simulation, agents affiliated with a supernatural worldview club were significantly more likely $(M=44.3 \%, S D=0.51)$ than those not affiliated with a worldview club $(M=21.0 \%, S D=0.40)$ to be actively prosocial $t(14374)=24.4, p<0.01$. When tribal prosociality was excluded, $(M=31.3 \%, S D=0.45)$ agents affiliated with a supernatural worldview club still exhibited active prosociality at a significantly higher level than the unaffiliated $(M=21.0 \%, S D=0.40), t(15893)=$ $10.8, p<0.01$. The higher frequency of prosocial actions was attributable the additional social network of the supernatural worldview club in which affiliated agents received more prosocial action opportunities of each 


\begin{tabular}{|c|c|c|c|c|}
\hline RQ \# & METHOD & ALL ACTIONS & EXCLUDING TRIBAL ACTIONS & $\begin{array}{l}\text { PASSIVE PROSOCIALITY } \\
\text { TRUST (TR); TOLERANCE (TOL) }\end{array}$ \\
\hline$\# 1$ & Data Analysis & Yes $(p<0.01)$ & Yes $(p<0.01)$ & Tr: Yes $(p<0.01)$; Tol: Yes $(p<0.01)$ \\
\hline$\# 1$ & Simulation & Yes $(p<0.01)$ & Yes $(p<0.01)$ & Tr: Yes $(p<0.01)$; Tol: Yes $(p<0.01)$ \\
\hline$\# 2$ & Data Analysis & Yes $(p<0.01)$ & No $(p=0.54)$ & Tr: Yes $(p<0.01)$; Tol: Yes $(p<0.01)$ \\
\hline \#2 & Simulation & Yes $(p<0.01)$ & No $(p=0.53)$ & Tr: Yes $(p<0.01) ;$ Tol: Yes $(p<0.01)$ \\
\hline \#3 & Data Analysis & NA & NA & Tr: Yes $(p<0.01) ;$ Tol: Yes $(p<0.01)$ \\
\hline \#3 & Simulation & NA & NA & Tr: 0.51 vs. 0.51 ; Tol: Yes $(p<0.01)$ \\
\hline \#4 & Data Analysis & NA & NA & Tr: Yes ( $p<0.01)$; Tol: No $(p=0.03)$ \\
\hline \#4 & Simulation & NA & NA & Tr: Yes $(p<0.01) ;$ Tol: No $(p=0.04)$ \\
\hline
\end{tabular}

Table 2 Summary of Results for Research Questions.

type. Thus, even though affiliated and unaffiliated agents accepted prosocial action opportunities at the same rate, affiliated agents were more regularly presented with prosocial action opportunities. These dynamics within the simulation are shown in Figure 7.

\section{Passive Prosociality}

Based on WVS data, individuals affiliated with a supernatural worldview club had significantly lower levels of trust $(M=26.0 \%, S D=0.44)$ than the unaffiliated $(M=28.0 \%, S D=0.45), t(15622)=-2.82, p<0.01$.

The agent-based simulation yielded similar results to the WVS trust data. Recall, trust was operationalized as the total size of an agent's social networks relative to maximum size of all agents' social networks. In the simulation, the average trust score for agents affiliated with supernatural worldview clubs $(M=0.46, S D=0.23$ ) was significantly lower than the average trust score for unaffiliated agents $(M=0.54, S D=0.26), t(15823)=$ $-8.81, p<0.01$

In the $A B M$, relative to affiliated agents, unaffiliated agents had a larger total social network (and thus higher trust score) because of their larger online and offline social networks. This was attributable to the lower number of negative interactions that the unaffiliated had with outgroup agents, making the outgroup agents less likely to be removed from their networks. Despite the additional social network of affiliated agents (i.e., their worldview club), the higher removal rate of outgroup agents from their social network was large enough to account for the difference in total social network size. Figure 8 illustrates this dynamic.

Based on the WVS data, individuals affiliated with supernatural worldview clubs had lower tolerance $(M=$ $91.2 \%, S D=0.28)$ than the unaffiliated $(M=93.2 \%, S D=$ $0.25), t(14892)=-4.77, p<0.01$.

In the $A B M$ simulation, the average tolerance score was also lower for agents affiliated with supernatural worldview clubs $(M=0.72, S D=0.21)$ relative to the unaffiliated $(M=0.79, S D=0.23), t(16392)=-6.54, p$ $<0.01$. In the simulation this occurs because outgroup suspicion (inverse tolerance) was one of the conditions that, when interacting with other conditions, may have led an agent to affiliate with a supernatural worldview club. This created a social network for an affiliated agent in which the average member was likely to have had lower tolerance values than the rest of the population. Furthermore, the within-network interactions were likely to decrease or maintain an agent's tolerance because the majority-majority interactions with the supernatural worldview club social network were with agents likely to have lower tolerance. These dynamics are highlighted in Figure 9.

\section{RESEARCH QUESTION \#2: IS PROSOCIALITY BASED ON SUPERNATURAL WORLDVIEW?}

\section{Active Prosociality}

Within the WVS data, those with supernatural worldview were more actively prosocial (i.e., voluntary acts) than those with a naturalist worldview $(M=32.4 \%, S D=$ 0.47 versus $M=26.2 \%, S D=0.44$ respectively), $t(1729)$ $=5.04, p<0.01$. However, when excluding tribal active prosociality, these two groups no longer significantly differed $(M=26.1 \%, S D=0.44$ versus $M=26.2 \%, S D=$ $0.44, t(28758)=0, p<0.01)$.

The agent-based simulation yielded very similar results. Agents with supernatural worldviews were more likely to be actively prosocial $(M=31.7 \%, S D=$ 0.41 ) than agents without supernatural worldviews ( $M$ $=26.8 \%, S D=0.40), t(1843)=4.91, p<0.01$. However, when tribal prosociality was excluded, active prosociality was equivalent between those with $(M=26.8 \%$, SD = $0.40)$ and without $(M=26.8 \%, S D=0.40)$ a supernatural worldview, $t(28758)=0, p<0.01$. In the $A B M$, this occurred because: (1) agents were required to have a supernatural worldview to be affiliated a supernatural worldview club and (2) only agents affiliated with a supernatural worldview club had tribal prosocial actions generated for them.

Because those agents with a supernatural worldview had an additional source of prosocial action opportunities (i.e., tribal ones) they received more 


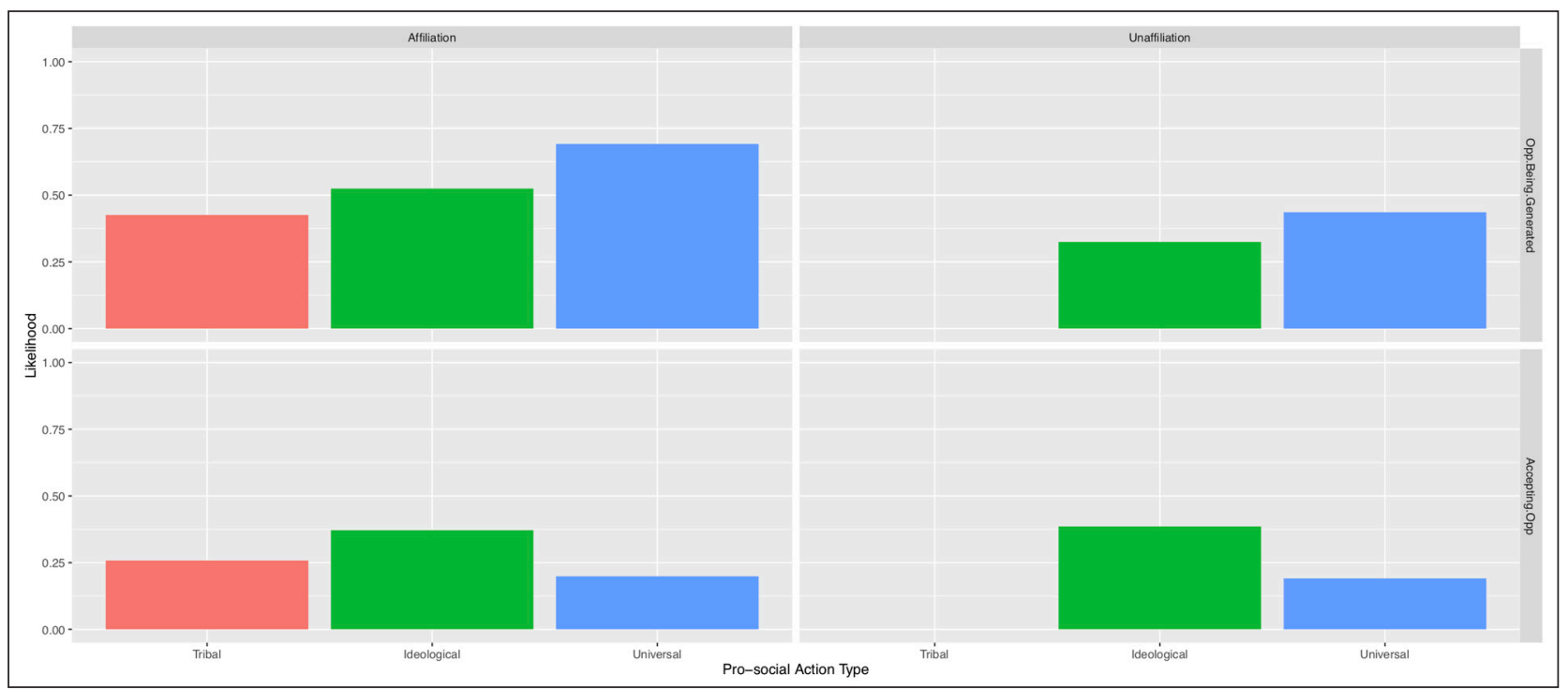

Figure 7 The Average Likelihood of Each Type of Prosocial Action Opportunity Generated and Accepted for Affiliated and Unaffiliated Agents.

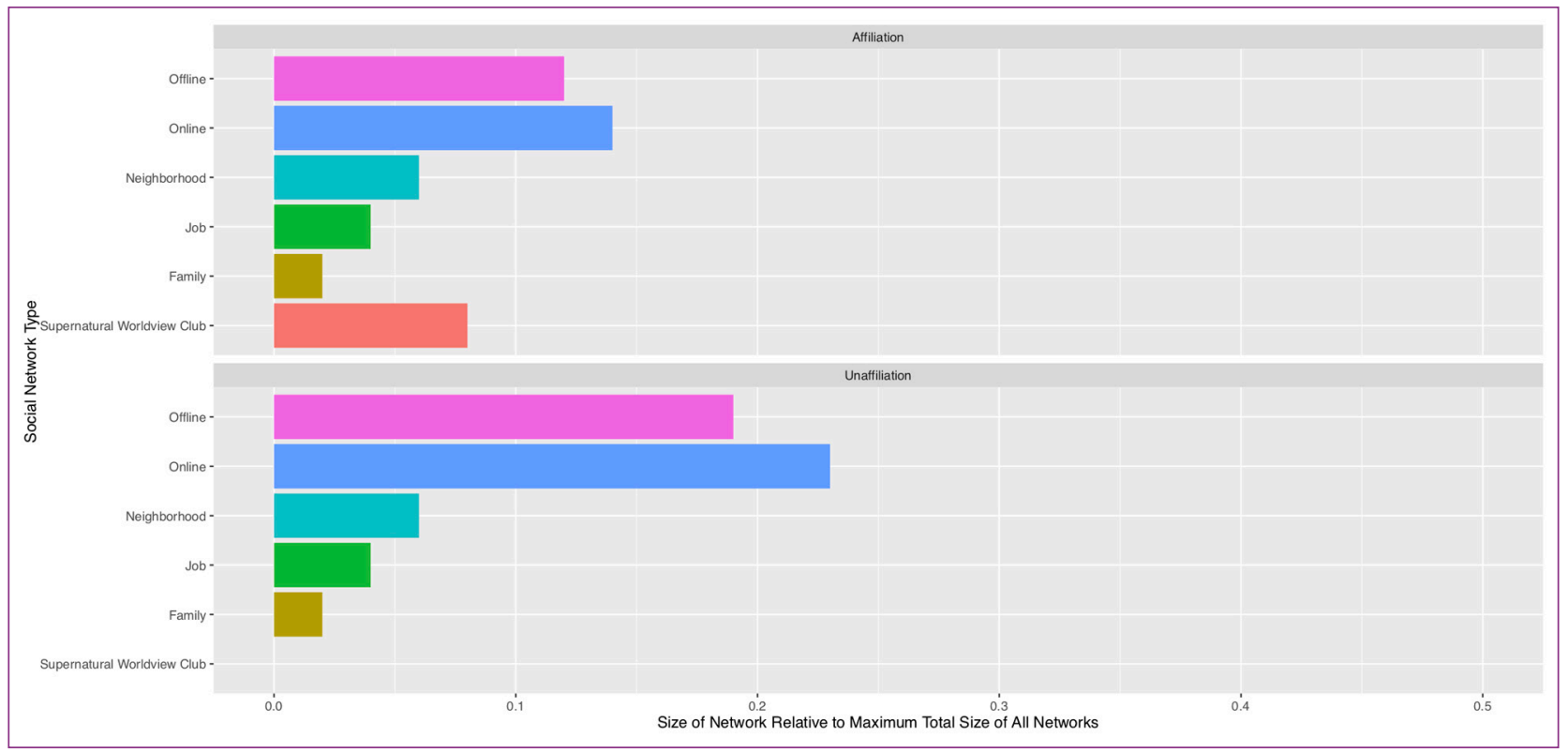

Figure 8 The Size of Social Network Types Relative to Maximum Total Size of all Social Networks by Type of Affiliation.

action opportunities. This dynamic was absent when tribal prosocial actions were excluded from the analysis. Unaffiliated individuals with a supernatural worldview were the least prosocially active group because they had higher outgroup suspicion than those with a naturalist worldview, which limited the size of their online and offline social networks. Higher outgroup suspicion was attributable to the inclusion of individuals who recently left a supernatural worldview club due to: (1) negative interactions with members of the club or (2) inconsistent actions from the exemplar along with an outgroup suspicion value below the specified threshold. The time these individuals spent with the worldview club increased their outgroup suspicion and limited the number of prosocial opportunities generated for them as shown in Figure 9.
Figure 10 shows that all three groups accepted prosocial action opportunities at the same rate. However, it also shows significantly fewer opportunities were generated for unaffiliated individuals with a supernatural worldview. Figure 11 illustrates how this was attributable to the lower number of opportunities available, which in turn was a result of smaller social networks relative to unaffiliated individuals with a naturalist worldview.

\section{Passive Prosociality}

Our analyses of the WVS data showed that individuals with supernatural worldviews had lower trust levels $(M=26.1 \%$, $S D=0.44)$ than those without supernatural worldviews ( $M$ $=36.6 \%, S D=0.48), t(1640)=-7.88, p<0.01$.

The agent-based simulation yielded similar results in that the average trust score was lower for agents with 


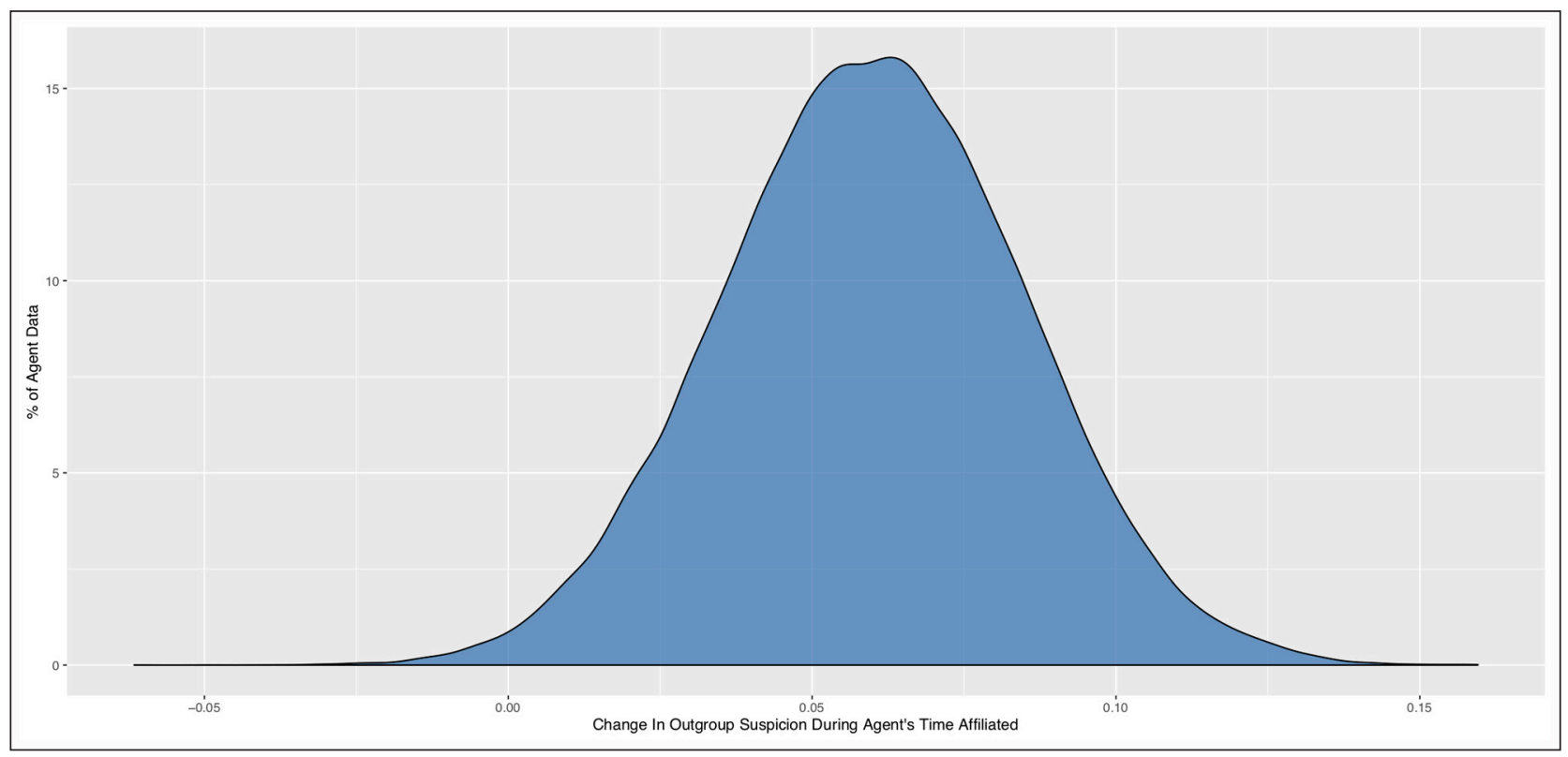

Figure 9 The Change in Outgroup Suspicion (Inverse Tolerance) During Time Affiliated With Supernatural Worldview Clubs.

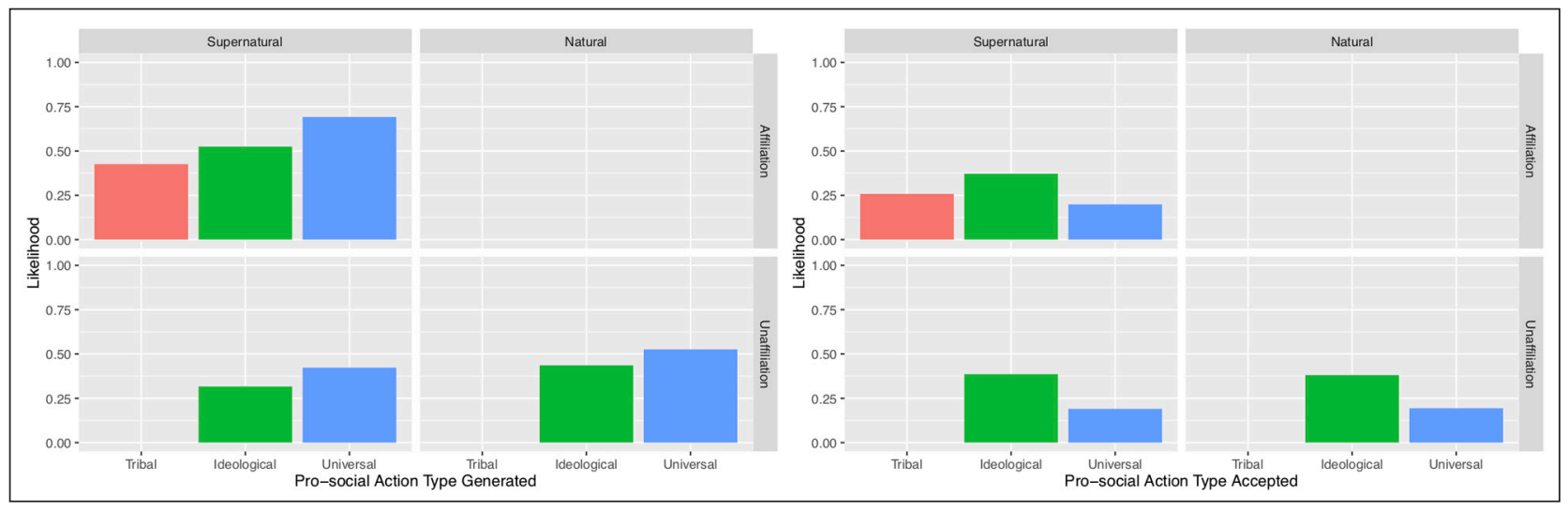

Figure 10 The Likelihood of Prosocial Action Opportunity Type Generated and Accepted by Worldview and Affiliation status.

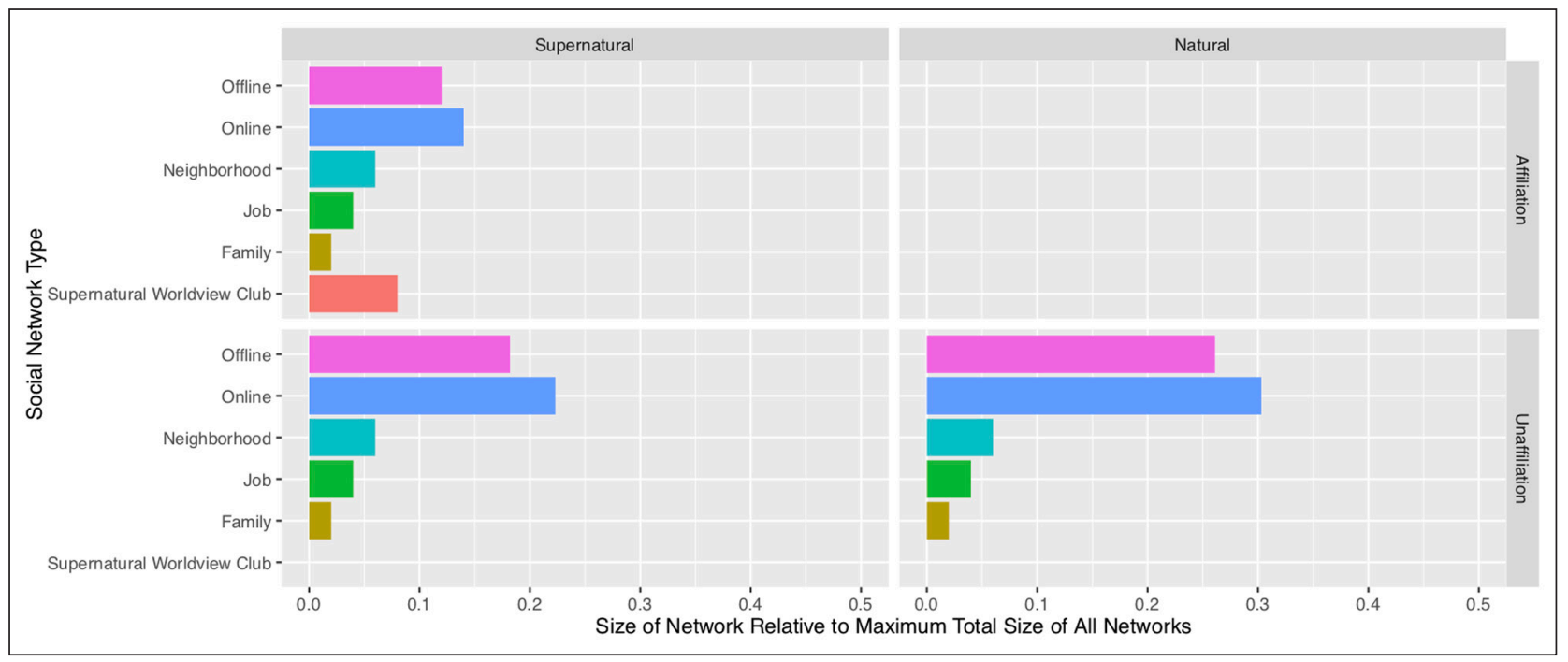

Figure 11 The Social Network Size by Worldview and Affiliation Status.

supernatural worldviews $(M=0.49, S D=0.46)$ than for those with naturalist worldviews $(M=0.68, S D=0.51)$, $t(1921)=-8.16, p<0.01$
Within the context of the simulation, agents with a naturalist worldview had a larger total social network (and thus higher trust score) than affiliated agents 
because unaffiliated agents had larger online and offline social networks. The difference in the size of the online and offline social networks occurred because agents with a naturalist worldview were less likely to have negative interactions with outgroup agents due to their greater tolerance (lower outgroup suspicion). This made agents with a naturalist worldview less likely to remove outgroup agents from their online and offline social networks. The difference in degree of removal of outgroup agents as a function of worldview is noteworthy (just as it was for affiliated agents in Research Question \#1). On the one hand, those agents with a supernatural worldview had an additional social network that agents with a naturalist worldview did not have, a supernatural worldview club. However, the rate at which agents with a supernatural worldview removed outgroup agents from their network was large enough to result in a significantly smaller social network size than agents with a naturalist worldview (see Figure 12). Thus, any expansive effect of the supernatural worldview club on network size was offset by outgroup agent removal.

Furthermore, the social network size for unaffiliated agents with a supernatural worldview were still smaller than those with a naturalist worldview. This was attributable to the inclusion of individuals who recently left a supernatural worldview club due to: (1) negative interactions with the exemplar agent in the club or (2) inconsistent actions from the exemplar paired with tolerance above the specified threshold. This resulted in lower than average tolerance for unaffiliated agents with a supernatural worldview which created smaller online and offline social networks than individuals with a naturalist worldview.
Based on the WVS data, individuals with supernatural worldviews had lower tolerance $(M=92.1 \%, S D=0.27)$ than those with naturalist worldviews $(M=94.0 \%, S D=$ $0.24), t(1772)=-2.66, p<0.01$.

Likewise, in the ABM simulation, the average tolerance score was lower for agents with supernatural worldviews $(M=0.78, S D=0.56)$ than those with naturalist worldviews $(M=0.86, S D=0.58), t(1948)=-6.81, p<0.01$.

In the simulation, this occurs because the group of individuals with a supernatural worldview included: (1) agents affiliated with a supernatural worldview club and (2) agents who previously were part of a supernatural worldview club but later became unaffiliated and (3) agents with a supernatural worldview who never affiliated. Recall that affiliated agents had lower tolerance than unaffiliated agents. However, among unaffiliated agents, those with supernatural worldviews had even lower tolerance than those with naturalist worldviews. This occurred because a previous affiliation with a supernatural worldview club tended to result in agents who retained their supernatural worldview even subsequent to disaffiliation. These agents had a higher outgroup suspicion value (and thus lower tolerance score) than agents who were never affiliated with a supernatural worldview club. In the simulation it took a significant amount of time for these previously affiliated agents to dramatically change their tolerance.

\section{RESEARCH QUESTION \#3: DO CHANGES IN PASSIVE PROSOCIALITY PRECEDE CHANGES IN WORLDVIEW?}

Two measures of passive prosociality were assessed in the longitudinal WVS data. There was no significant

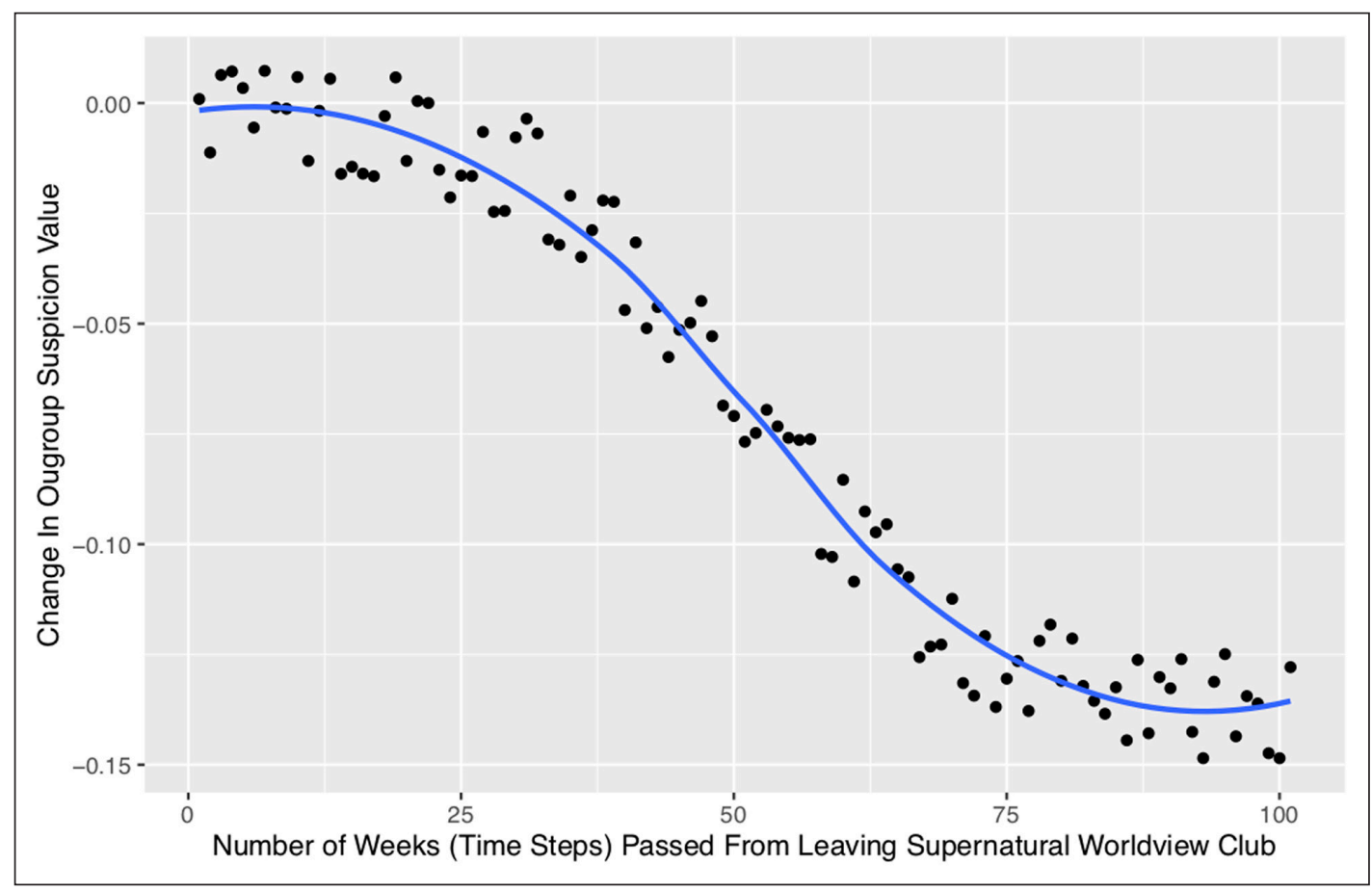

Figure 12 Average change in Outgroup Suspicion (Inverse Tolerance) After Disaffiliating With a Supernatural Worldview Club. 
difference in level of trust between those who changed their worldview from supernatural to naturalist $(M=$ $35.4 \%, S D=0.48)$ and those who changed from naturalist to supernatural $(M=34.9 \%, S D=0.48), t(9176)=0.43, p$ $=0.66)$. However, prior tolerance was higher in those who changed their worldview from supernatural to naturalist $(M=94.3 \%, S D=0.23)$ than individuals who changed worldview from naturalist to supernatural $(M=92.1 \%, S D$ $=0.27), t(5629)=3.44, p<0.01$.

Within the context of the simulation we distinguished between agents who changed their worldview from supernatural to naturalist (or vice versa) using the following criteria: the agent must have had their previous worldview for 26 time steps prior to the worldview change and must have kept their new worldview for 26 time steps after the change. Using these criteria for the ABM, a pattern similar to the WVS results emerged. Trust levels were the same $(M=0.51$, $S D=0.46)$ for agents who changed their worldview from supernatural to naturalist and for those $(M=0.51, S D$ $=0.45$ ) who changed from naturalist to supernatural, $t(8981)=0.18, p=0.51$. However, agents who changed their worldview from supernatural to naturalist were more likely to exhibit tolerance prior to the change $(M=0.84, S D=0.48)$ than agents who changed from naturalist to supernatural $(M=0.78, S D=0.46), t(6026)$ $=7.14, p<0.01$ ).

The modeling simulation revealed the dynamics underlying these processes. It was much more common for unaffiliated supernatural believers to transition over time to a naturalistic worldview, and almost all agents with such a transition were unaffiliated. Since having a supernatural worldview was a precondition to affiliating with a supernatural worldview club, every agent that transitioned from a naturalistic to a supernatural worldview was initially unaffiliated, by definition. Most of the interactions that caused these agents to become conflicted with their naturalistic worldview occurred with homophilous (i.e., sharing the agent's minority or majority status) agents who had low levels of tolerance, which increased the likelihood of transition to affiliation with a supernatural worldview club. As outlined above, although affiliated agents had larger club-based social networks, they also had smaller outgroup networks, which reduced the chances of encounters that could lead to worldview conflict. Those agents who changed from supernatural to naturalistic worldviews had high tolerance, making it more likely that they would have positive interactions with alter agents of a different majority/minority designation. This further increased tolerance and maintained the size of their social networks. As a result, agents' chances of having a conflictual interaction regarding their supernatural worldview increased, ultimately leading them in a naturalistic direction.

\section{RESEARCH QUESTION \#4: DO CHANGES IN PASSIVE PROSOCIALITY PRECEDE CHANGES IN AFFILIATION WITH WORLDVIEW CLUBS?}

Based on the longitudinal WVS data, levels of trust prior to affiliation change were higher for those who changed their status from affiliated to unaffiliated with a supernatural worldview club $(M=22.5 \%, S D=0.41)$ compared to those who changed from unaffiliated to affiliated $(M=18.5 \%, S D=0.39), t(9176)=4.88, p$ $<0.01$. Regarding levels of tolerance, there was not a statistically significant difference $t(9160)=-2.3117, p$ $=0.028$ ), between individuals holding a supernatural worldview who changed from affiliated to unaffiliated ( $M$ $=90.8 \%, S D=0.29)$ and individuals who changed from unaffiliated to affiliated $(M=92.0 \%, S D=0.27)$. The lack of a statistically significant difference here is because we set our threshold for statistical significance at 0.01 .

Within the context of the simulation we distinguished between agents who changed their affiliation status but maintained a supernatural worldview using the following criteria: the agent must have had a supernatural worldview and their affiliation status for 26 time steps prior to the affiliation change and must have kept their new affiliation status and a supernatural worldview for 26 time steps after the affiliation. Data collection for the passive prosociality prior to the affiliation status change reflects the average trust and tolerance score prior to the agent's affiliation change.

Similar to the WVS results, in the ABM simulation levels of trust prior to change in agents' affiliation status differed as a function of the direction of change. Agents who disaffiliated exhibited more trust $(M=0.51, S D=$ $0.37)$ than agents who changed from unaffiliated to affiliated $(M=0.44, S D=0.35), t(9236)=5.97, p<0.01$. In contrast, agents with a supernatural worldview who disaffiliated did not differ in levels of tolerance $(M=0.73$, $S D=0.41)$ from agents who changed from unaffiliated to affiliated $(M=0.74, S D=0.40), t(9058)=-1.09, p=$ 0.04 . The lack of a statistically significant difference here is because we set our threshold for statistical significance at 0.01 .

In the simulation, these patterns were attributable to both groups of agents having had low tolerance values (high outgroup suspicion values) prior to their change. Recall that the interactions resulting from affiliation in a supernatural worldview club, even for those affiliated agents who eventually became unaffiliated, limited their tolerance values. Furthermore, the majority (64\%) of unaffiliated agents with a supernatural worldview who later became affiliated did so because they achieved a tolerance value that was sufficiently low to qualify them for affiliation, even if they acted in a manner inconsistent with a supernatural worldview. The 26 time steps of tolerance data for the agents who later became affiliated indicated that their tolerance steadily decreased as their decision to become affiliated approached. Consequently, 
tolerance levels did not differ as a function of change in affiliation.

The low tolerance (and high outgroup suspicion) for both groups resulted in smaller online and offline social networks. However, those individuals who were affiliated prior to their change had an additional social network that the unaffiliated agents did not: their supernatural worldview club. This resulted in higher trust scores for the affiliated agents prior to their choice to become unaffiliated. Since unaffiliated agents did not have this additional social network prior to affiliation they initially had lower trust scores.

\section{DISCUSSION}

Can the use of modeling and simulation in conjunction with real-world data lend new perspectives to the types of complex problems involved in the study of (non)religion and prosociality? The interaction of numerous variables in dynamic, multi-causal, recursive relationships in these phenomena has made research in this field difficult. The statistical and modeling analyses reported here focus on these types of variables, including prosocial outcomes that operate as a function of changes in individuals' worldview beliefs, group affiliation, and social network properties. Taken together, data from the WVS and the ABM simulation studies paint a similar picture of how prosociality is shaped by group affiliation and worldviews. Both data sets indicated that individuals' affiliation was more relevant to predicting prosocial behaviors than their worldview beliefs, whether religious or secular. Relatedly, the higher level of prosociality seen among those with supernatural, as compared to naturalistic, beliefs is primarily attributable to the fact that the former also tend to be affiliated with a worldview club.

The unique capacities of ABM are best exemplified in their ability to tease out the effects of several mechanisms unfolding at the same time. One such result pertains to the process by which active prosociality manifests in tribal (as opposed to universal) forms. As noted in the introduction, it has long been observed that the higher ingroup prosociality associated with religiouslyaffiliated groups tends to exist along with tribal or parochial attitudes (Putnam \& Campbell, 2010). The ABM analysis illustrates how variation in active volunteering, as well as tolerance and trust, are affected by agents' social network parameters. Agents with supernatural worldviews performed more prosocial actions than those with a naturalistic worldview but only for tribal, not universal, actions. The ABM illustrated how the more extensive within-group social contacts and the greater number of opportunities provided by supernatural worldview clubs promoted active prosociality in the form of volunteering for their members, while at the same time limiting their contact with outside-group alters, thereby increasing homophily. This illustrates the paradox of group affiliation at the core of the diverging patterns of religious and nonreligious prosociality. The social network factors of supernatural worldview groups that boost active prosociality also corrode passive prosociality such as tolerance of different others.

Why does tolerance tend to be characteristic of the nonreligious rather than the religious? The simulation studies also provide further information about the pattern, mentioned above, by which religious affiliation appears to coincide with lower tolerance of outgroup members. The same club membership effect that creates opportunities for tribal prosocial helping also increases outgroup suspicion and network homophily. The ABM helps to reveal the dynamics that drive this process. In the simulation, the majority-majority or minorityminority interactions of agents within the club network tended to be with alters who themselves had high levels of outgroup suspicion, which increased agents' own suspicion. This "homophilizing" effect led to affiliated agents' purging divergent alters from their network. By contrast, the unaffiliated were less likely to have negative interactions with outgroup alters, who were less likely to be removed from their networks, a process which boosted tolerance by allowing a diverse network.

How are qualities of tolerance and trust related to the process of changing beliefs and affiliation? As with previous studies (Loveland, Capella \& Maisonet 2017; Welch, Sikkink \& Loveland 2007) our analysis indicated that individuals with a naturalistic worldview are more trusting and tolerant of others than individuals with a supernatural worldview (especially when the latter are religiously affiliated). The WVS longitudinal data indicated that those who changed from religious belief to nonbelief were more likely earlier on to display tolerance of others, compared to individuals whose belief changes went in the other direction. Likewise, those who eventually disaffiliated from a supernatural worldview club were more likely to display trust of others prior to disaffiliation compared to those individuals who become affiliated. This illustrates some distinctness in indices: for worldview change, previous tolerance is more relevant; for changes in affiliation, previous trust is more important.

The capacity of the $A B M$ to simulate repeated interactions over time provides a greater understanding of how the process of change plays out in agents' social networks. The low outgroup suspicion values of agents who changed from supernatural to naturalistic worldviews led to more positive interactions with agents of a different majority/minority designation, which further reduced outgroup suspicion and produced a heterogeneous social network. In this way, we see that social diversity (or low parochialism) can play a causal role in changing supernatural worldviews. This is reminiscent of the processes of polarization, discussed in the introduction, in which early differences in personality 
lead to self-selection into different environments, thereby potentiating further change. In practical terms, the solitary journey reported by many apostates may be attributable to a form of survivor bias: those who questioned religious worldviews but who did receive social support from religious individuals in their environment may have retained their faith, which prevented them from disaffiliation or secularization.

\section{IMPLICATIONS}

ABM methodologies are increasingly being used in the scientific study of nonreligion and secularity to illuminate these complex social processes. Here we have shown how this methodology, in conjunction with other approaches such as statistical analysis of real-life survey data sets, can illuminate the causal dynamics shaping the relationship between religion and prosociality. We think that such tools can be helpful whenever scholars of nonreligion and secularity are faced with complex phenomena about which there are multiple testable theories aimed at determining the causal role of specific types of beliefs and behaviors operating within complex social relationships. Currently in the field of the cognitive sciences of religion there are vigorous debates over the relative contribution of traits such as analytical cognition, faith in intuition, actively open-minded thinking, anthropomorphic tendencies, and other modes of thought that have been linked to lower religious and spiritual belief. Other members of our research team are developing models that address these issues.

As noted in the introduction, there is a current theoretical debate regarding the necessity or role of religion in establishing prosocial norms. As was demonstrated in the present findings, secular prosociality in the form of greater outgroup trust, openness, and tolerance of social heterogeneity, is more common among nonreligious agents. However, active prosociality in forms such as volunteering, charity, and other types of civic participation, is relatively less-developed among secularists, who may need alternative mechanisms that facilitate further improvement. As we have seen, one mechanism used to great effect by religious groups (although not requiring supernatural belief) is the promotion of participation in groups with close social ties, exposure to prosocial models and norms (exemplars), and frequent requests and opportunities for volunteering. The study of specifically nonreligious and secular groups is relatively new, with only a limited range of secular clubs for comparison. But clearly, niches are being filled by groups with differing emphases. For example, Sunday Assembly, the Center for Inquiry, and other humanist groups span a range of agendas (Cimino \& Smith 2014; Smith 2017). Although not all secular or nonreligious groups prioritize prosociality, those that do so likely utilize the same social capital-generating mechanisms that are present in any group that effectively promotes prosociality.

Another specific implication of the current results for secularism pertains to the relationship between diverse social networks and negative attitudes towards the nonreligious because of their perceived immorality (Gervais et al. 2017). Our results indicated that increasing the heterogeneity of networks by the inclusion of naturalistic examplars may decrease distrust of the nonreligious in general. Other research has shown that when religious people are made aware that atheists are more common than they originally supposed, this reduces distrust in atheists (Gervais, Sheriff \& Norenzayan 2011). We also found that positive contact with the non-religious or non-affiliated could increase levels of tolerance. Therefore, the nonreligious may benefit from becoming more visible in the broader community and embodying prosociality in a way that contradicts common stereotypes.

\section{LIMITATIONS AND FUTURE WORK}

One limitation of the present model is the number of variables included. It would be productive for future studies to also include alternative individual difference variables such as personality, cognitive, and demographics parameters, which are known or suspected to be closely tied to both social functioning and religiosity (or the lack thereof). One variable that should be given future consideration is the strength of worldview conviction (e.g., importance of beliefs). The degree of conviction with which individuals hold their worldviews or the importance they place on them is arguably of greater importance than belief content (Galen \& Kloet 2011b). Whereas most research has treated devout religious individuals as being the polar opposite of staunch atheists, they actually share the commonality of being strongly committed to their worldview. Belief strength is reflected in prosocial behaviors as well. Petrovic et al. (2018) found that religious attendance frequency correlated with the overall likelihood of volunteering, but individuals' personal importance of religion predicted the amount of time spent volunteering. Including such variables could improve both the explanatory and predictive power of models.

Related research has shown that the inclusion of worldview intensity, gender and education-level enabled an agent-based model to forecast existential security more accurately than several competing statistical models (Gore et al. 2018). The results of the latter study showed in social networks where the majority of agents have completed post-secondary 
education, agents have on average a steeper decline in their religious practices and belief in God than agents connected to social networks where the majority of agents have not completed post-secondary education. This dynamic enables the agent-based model, for a given country and a given time period, to provide a more accurate forecast of changes in the existential security and the religiosity than two alternative approaches for a specific time period for specific countries. In future work, we plan to highlight how the inclusion of these types of variables within our model creates a more detailed explanation of the patterns observed in the WVS. In addition, we will evaluate the ability of the prosociality model presented here to forecast outcomes related to the model's operationalization of prosociality.

Another factor that may be useful to include in future modeling studies is the degree of normative fit between agents' worldviews and their broader environment or network. An atheist living in the southern United States shares at least one thing in common with an evangelical Christian living in downtown Copenhagen: in their environment, they are atypical. The relationship between individuals' religiosity and prosociality varies as a function of the cultural emphasis or norms regarding religion (Stavrova \& Siegers 2014). Future computer models should therefore incorporate variables representing the degree of fit between agent's worldview vis a vis the predominant worldview of the culture in which he or she is embedded.

Despite their limitations, we have argued that ABM methods can be a valuable addition to the research toolkit of scholars of secularism and nonreligion.

\section{SUPPLEMENTARY MATERIALS}

Link to online repository of supplementary materials https://github.com/rossgore/modrna-publication.

\section{ACKNOWLEDGEMENTS}

The authors are grateful to all the members of the Modeling Religion in Norway (MODRN) project for helpful conversations throughout the process, but special thanks goes to Phil Zuckerman and David Pollock for their input into early versions of the model and to the developers of the Artificial Society Analysis Platform upon which the former was based.

\section{FUNDING INFORMATION}

Funding for this research was provided by The Research Council of Norway, grant \#250449.

\section{COMPETING INTERESTS}

The authors have no competing interests to declare.

\section{AUTHOR CONTRIBUTIONS}

Luke Galen, Ross Gore and F. LeRon Shults conceived and designed the model. Ross Gore and Luke Galen developed the model and performed the experiments. Luke Galen, Ross Gore and F. LeRon Shults wrote the paper.

\section{AUTHOR AFFILIATIONS}

\section{Luke Galen}

Grand Valley State University, US

Ross Gore (D) orcid.org/0000-0003-4065-6146

Old Dominion University, US

F. LeRon Shults (iD) orcid.org/0000-0002-0588-6977

University of Agder, NO

\section{REFERENCES}

Altemeyer, B and Hunsberger, B. 1997. Amazing Conversions: Why some Turn to Faith and Others Abandon Religion. Amherst, NY: Prometheus Books.

Atkinson, QD and Bourrat, P. 2011. Beliefs about God, the afterlife and morality support the role supernatural policing in human cooperation. Evolution \& Human Behavior, 32: 41-49. DOI: https://doi.org/10.1016/j. evolhumbehav.2010.07.008

Axelrod, RM. 1997. The Complexity of Cooperation: AgentBased Models of Competition and Collaboration. Princeton: Princeton University Press. DOI: https://doi. org/10.1515/9781400822300

Balliet, D and Van Lange, PAM. 2013. Trust, punishment and cooperation across 18 societies: a meta-analysis. Perspectives on Psychological Science, 8: 363-379. DOI: https://doi.org/10.1177/1745691613488533

Barber, N. 2011. A cross-national test of the uncertainty hypothesis of religious belief. CrossCultural Research, 45(3): 318-333. DOI: https://doi. org/10.1177/1069397111402465

Becker, P and Dhingra, P. 2001. Religious involvement and volunteering: Implications for civil society. Sociology of Religion, 62: 315-335. DOI: https://doi. org/10.2307/3712353

Beyerlein, K and Hipp, JR. 2006. From pews to participation: The effect of congregation activity and context on bridging civic engagement. Social Problems, 53: 97-117. DOI: https:// doi.org/10.1525/sp.2006.53.1.97

Borgonovi, F. 2008. Divided we stand, united we fall: Religious pluralism, giving and volunteering. American Sociological Review, 73: 105-128. DOI: https://doi. org/10.1177/000312240807300106 
Burge, R. 2019. Are evangelicals more altruistic than other groups? Christianity Today. https://www.christianitytoday. com/edstetzer/2019/april/are-evangelicals-more-altruisticthan-other-groups.html.

Cheadle, JE and Schwadel, E. 2012. The 'friendship dynamics of religion,' or the 'religious dynamics of friendship'? A social network analysis of adolescents who attend small schools. Social Science Research, 41: 1198-1212. DOI: https://doi.org/10.1016/j.ssresearch.2012.03.014

Cimino, R and Smith, C. 2014. Atheist Awakening: Secular Activism and Community in America. New York: Oxford University Press. DOI: https://doi.org/10.1093/acprof:o so/9780199986323.001.0001

Cragun, RT. 2013. What You Don't Know About Religion (But Should). Durham, NC: Pitchstone Publishing.

Einolf, CJ. 2011. The link between religion and helping others: The role of values, ideas, and language. Sociology of Religion, 72: 435-455. DOI: https://doi.org/10.1093/socrel/srr017

Emerson, MO and Sikkink, D. 2006. Portraits of American Life Study, 1st Wave.

Epstein, JM and Axtell, R. 1996. Growing Artificial Societies: Social Science from the Bottom Up. Cambridge: The MIT press. DOI: https://doi.org/10.7551/mitpress/3374.001.0001

Festinger, L, Riecken, HW and Schachter, S. 1956. When Prophecy Fails. Minneapolis: University of Minnesota Press. DOI: https://doi.org/10.1037/10030-000

Florida, R, Mellander, C and Stolarick, K. 2008. Inside the black box of regional development. Human capital, the creative class and tolerance. Journal of Economic Geography, 8: 615-649. DOI: https://doi.org/10.1093/jeg/lbn023

Galanter, M. 1980. Psychological induction into the largegroup: Findings from a modern religious sect. The American Journal of Psychiatry, 137 (12): 1574-1579. DOI: https://doi. org/10.1176/ajp.137.12.1574

Galen, LW and Kloet, J. 2011a. Personality and social integration factors distinguishing non-religious from religious groups: The importance of controlling for attendance and demographics. Archive for the Psychology of Religion, 33: 205-228. DOI: https://doi. org/10.1163/157361211X570047

Galen, LW and Kloet, J. 2011b. Mental well-being in the religious and the non-religious: Evidence for a curvilinear relationship. Mental Health, Religion \& Culture, 14: 673-689. DOI: https://doi.org/10.1080/13674676.2010.510829

Galen, LW, Sharp, M and McNulty, A. 2015. The role of nonreligious group factors versus religious belief in the prediction of prosociality. Social Indicators Research, 122: 411-432. DOI: https://doi.org/10.1007/s11205-014-0700-0

Gervais, WM and Norenzayan, A. 2012. Like a camera in the sky? Thinking about God increases public self-awareness and socially desirable responding. Journal of Experimental Social Psychology, 48: 298-302. DOI: https://doi. org/10.1016/j.jesp.2011.09.006

Gervais, WM, Shariff, AF and Norenzayan, A. 2011. Do you believe in atheists? Distrust is central to anti-atheist prejudice. Journal of Personality and Social Psychology, 101:
1189-1206. DOI: https://doi.org/10.1037/a0025882

Gervais, WM, Xygalatas, D, McKay, RT, van Elk, M, Buchtel, EE, Aveyard, M and Bulbulia, J. 2017. Global evidence of extreme intuitive moral prejudice against atheists. Nature Human Behaviour, 1(8): 0151. DOI: https://doi.org/10.1038/ s41562-017-0151

Gore, R, Lemos, C, Shults, FL and Wildman, WJ. 2018. Forecasting changes in religiosity and existential security with an agent-based model. Journal of Artificial Societies and Social Simulation, 21: 1-31. DOI: https://doi. org/10.18564/jasss.3596

Guo, Q, Liu, Z and Tian, Q. 2018. Religiosity and prosocial behavior at national level. Psychology of Religion and Spirituality. DOI: https://doi.org/10.1037/rel0000171

Henrich, J, Ensimger, J, McElreath, R, Barr, A, Barrett, C, Bolyanatz, A and Ziker, J. 2010. Markets, religion, community size, and the evolution of fairness and punishment. Science, 327: 1480-84. DOI: https://doi. org/10.1126/science.1182238

Hunsberger, B, Alisat, S, Pancer, SM and Pratt, M. 1996. Religious fundamentalism and religious doubts: Content, connections, and complexity of thinking. International Journal for the Psychology of Religion, 6: 201-220. DOI: https://doi.org/10.1207/s15327582ijpr0603_7

Huuskes, L, Ciarrochi, J and Heaven, PCL. 2013. The longitudinal relationships between adolescent religious values and personality. Journal of Research in Personality, 47: 483-487. DOI: https://doi.org/10.1016/j. jrp.2013.04.010

Iannaccone, LR and Makowsky, MD. 2007. Accidental atheists? Agentbased explanations for the persistence of religious regionalism. Journal for the Scientific Study of Religion, 46(1): 1-16. DOI: https://doi.org/10.1111/j.14685906.2007.00337.x

Johnson, DDP. 2005. God's punishment and public goods - a test of the supernatural punishment hypothesis in 186 world cultures. Human Nature, 16(4): 410-46. DOI: https:// doi.org/10.1007/s12110-005-1017-0

Krause, $\mathbf{N}$ and Ellison, CG. 2009. The doubting process: A longitudinal study of the precipitants and consequences of religious doubt. Journal for the Scientific Study of Religion, 48: 293-312. DOI: https://doi.org/10.1111/j.14685906.2009.01448.x

Lam, PY. 2002. As the flocks gather: How religion affects voluntary association participation. Journal for the Scientific Study of Religion, 41: 405-422. DOI: https://doi. org/10.1111/1468-5906.00127

Lane, J. 2018. Strengthening the supernatural punishment hypothesis through computer modeling. Religion, Brain \& Behavior, 8(3): 290-300. DOI: https://doi.org/10.1080/21535 99X.2017.1302977

Lane, JE, Shults, FL and McCauley, RN. 2019. Modeling and simulation as a pedagogical and heuristic tool for developing theories of cognitive science: An example from ritual competence theory. In: Diallo, S, Wildman, WJ, Shults, FL and Tolk, A (eds.), Human Simulation: Perspectives, 
Insights, and Applications. Cham: Springer, pp. 143-154 DOI: https://doi.org/10.1007/978-3-030-17090-5_8

Lewis, VA, MacGregor, CA and Putnam, RD. 2013. Religion, networks, and neighborliness: The impact of religious social networks on civic engagement. Social Science Research, 42: 331-346. DOI: https://doi.org/10.1016/j. ssresearch.2012.09.011

Lim, C and MacGregor, CA. 2012. Religion and volunteering in context disentangling the contextual effects of religion on voluntary behavior. American Sociological Review, 77: 747779. DOI: https://doi.org/10.1177/0003122412457875

Loveland, MT, Capella, AG and Maisonet, I. 2017. Prosocial skeptics: Skepticism and generalized trust. Critical Research on Religion, 5(3): 251-265. DOI: https://doi. org/10.1177/2050303217707245

Low, N, Butt, S, Ellis, P and Davis Smith, J. 2007. Helping out: a national survey of volunteering and charitable giving. London: Cabinet Office.

Madsen, JK, Bailey, R, Carrella, E and Koralus, P. 2019. Analytic versus computational cognitive models: Agentbased modeling as a tool in cognitive sciences. Current Directions in Psychological Science, 28: 299-305. DOI: https://doi.org/10.1177/0963721419834547

Makowsky, MD. 2019. When average is irrelevant: Computational modeling of religious groups. In Advances in the Economics of Religion. Springer, pp. 61-72. DOI: https:// doi.org/10.1007/978-3-319-98848-1_4

McCullough, ME, Enders, CK, Brion, SL and Jain, AR. 2005. The varieties of religious development in adulthood: A longitudinal investigation of religion and rational choice. Journal of Personality and Social Psychology, 89(1): 78-89. DOI: https://doi.org/10.1037/0022-3514.89.1.78

McKay, R and Whitehouse, H. 2015. Religion and morality. Psychological Bulletin, 141(2): 447-473. DOI: https://doi. org/10.1037/a0038455

Merino, S. 2013. Religious social networks and volunteering: Examining recruitment via close ties. Review of Religious Research, 55: 509-527. DOI: https://doi.org/10.1007/ s13644-013-0113-6

Monsma, SV. 2007. Religion and philanthropic giving and volunteerism: Building blocks for civic responsibility. Interdisciplinary Journal of Religious Research, 3: 2-28.

Norenzayan, A, Shariff, AF, Gervais, WM and Willard, AK. 2016. The cultural evolution of prosocial religions. Behavioral and Brain Sciences, 39: e1 2016. DOI: https://doi. org/10.1017/S0140525X14001356

Norris, P and Inglehart, R. 2004. Sacred and Secular. Cambridge: Cambridge University Press. DOI: https://doi. org/10.1017/CBO9780511791017

Ozarak, EW. 1989. Social and cognitive influences on the development of religious beliefs and commitment in adolescence. Journal for the Scientific Study of Religion, 28: 448-463. DOI: https://doi.org/10.2307/1386576

Petrovic, K, Chapman, CM and Schofield, TP. 2018, November 29. Religiosity and volunteering over time: Religious service attendance is associated with the likelihood of volunteering, and religious importance with time spent volunteering. Psychology of Religion and Spirituality. DOI: https://doi.org/10.1037/rel0000236

Pew Research Center. 2014. Worldwide, many see belief in God as essential to morality. Retrieved from https://www. pewresearch.org/global/2014/03/13/worldwide-many-seebelief-in-god-as-essential-to-morality/

Price, ME and Launay, J. 2018. Increased wellbeing from social interaction in a secular congregation. Secularism and Nonreligion, 7(1): 6. DOI: https://doi.org/10.5334/snr.102

Prouteau, L and Sardinha, B. 2015. Volunteering and countrylevel religiosity: evidence from the European Union. Voluntas, 26: 242-266. DOI: https://doi.org/10.1007/ s11266-013-9431-0

Purzycki, BG, Apicella, C, Atkinson, QD, Cohen, E, McNamara, RA, Willard, AK and Henrich, J. 2016. Moralistic gods, supernatural punishment and the expansion of human sociality. Nature, 530: 327-330. DOI: https://doi. org/10.1038/nature16980

Putnam, RD. 2000. Bowling Alone: The Collapse and Revival of American Community. New York: Simon \& Schuster. DOI: https://doi.org/10.1145/358916.361990

Putnam, RD and Campbell, DE. 2010. American Grace: How Religion Divides and Unites Us. New York, NY: Simon \& Schuster.

Reynolds, CW. 1987. Flocks, herds and schools: A distributed behavioral model. ACM, 21(4): 25-24. DOI: https://doi. org/10.1145/37401.37406

Ruiter, S and De Graaf, ND. 2006. National context, religiosity and volunteering: Results from 53 countries. American Sociological Review, 71: 191-210. DOI: https://doi. org/10.1177/000312240607100202

Saroglou, V. 2006. Religion's role in prosocial behavior: Myth or reality? Psychology of Religion Newsletter, 31: 1-8. DOI: https://doi.org/10.1037/e568472011-002

Shariff, AF, Piazza, J and Kramer, SR. 2014. Morality and the religious mind: Why theists and nontheists differ. Trends in Cognitive Sciences, 18: 439-441. DOI: https://doi. org/10.1016/j.tics.2014.05.003

Shults, FL. 2018. Can we predict and prevent religious radicalization? In: Øverland, G (ed.), Violent Extremism in the 21st Century: International Perspectives. Cambridge: Cambridge Scholars Press, pp. 45-71.

Shults, FL, Gore, R, Wildman, WJ, Lynch, C, Lane, JE and Toft, M. 2018. A generative model of the mutual escalation of anxiety between religious groups. Journal of Artificial Societies and Social Simulation, 21(4): 1-25. DOI: https://doi. org/10.18564/jasss.3840

Shults, FL, Lane, JE, Diallo, S, Lynch, C, Wildman, WJ and Gore, R. 2018. Modeling terror management theory: Computer simulations of the impact of mortality salience on religiosity. Religion, Brain \& Behavior, 8(1): 77-100. DOI: https://doi.org/10.1080/2153599X.2016.1238846

Shults, FL, Wildman, WJ, Diallo, S, Puga-Gonzalez, I and Voas, D. 2020. The artificial society analytics platform. In: Verhagen, $\mathrm{H}$, et al. (eds.), Advances in Social Simulation, 
Springer Proceedings in Complexity. DOI: https://doi.

org/10.1007/978-3-030-34127-5_42

Shults, FL, Wildman, WJ, Lane, JE, Lynch, C and Diallo, S. 2018. Multiple axialities: A computational model of the axial age. Journal of Cognition and Culture, 18(4): 537-564. DOI: https://doi.org/10.1163/15685373-12340043

Smith, JM. 2017. Communal secularity: Congregational work at the Sunday Assembly. In: Cragun, RT, Manning, C and Fazzino, L (eds.), Organized Secularism. Berlin: De Gruyter Press, pp. 151-70. DOI: https://doi.org/10.1515/9783110458657-009

Stavrova, $\mathbf{O}$ and Siegers, P. 2014. Religious prosociality and morality across cultures: How social enforcement of religion shapes the effects of personal religiosity on prosocial and moral attitudes and behaviors. Personality and Social Psychology Bulletin, 40: 315-333. DOI: https://doi. org/10.1177/0146167213510951

Van der Meer, T, Te Grotenhuis, M and Pelzer, B. 2010. Influential cases in multilevel modeling: A methodological comment. American Sociological Review, 75: 173-178. DOI: https://doi.org/10.1177/0003122409359166
Wang, L and Graddy, E. 2008. Social capital, volunteering, and charitable giving. Voluntas, 19: 23-42. DOI: https://doi. org/10.1007/s11266-008-9055-y

Welch, MR, Sikkink, D and Loveland, MT. 2007. The radius of trust: religion, social embeddedness and trust in strangers. Social Forces, 86: 23-46. DOI: https://doi.org/10.1353/ sof.2007.0116

Whitehouse, H, François, P, Savage, PE, Currie, TE, Feeney, KC, Cioni, E and Turchin, P. 2019. Complex societies precede moralizing gods throughout world history. Nature, 568: 226. DOI: https://doi.org/10.1038/s41586019-1043-4

Wink, P, Dillon, M and Prettyman, A. 2007. Religiousness, spiritual seeking, and authoritarianism: Findings from a longitudinal study. Journal for the Scientific Study of Religion, 46(3): 321-35. DOI: https://doi.org/10.1111/j.14685906.2007.00361.x

Zuckerman, P. 2008. Society Without God: What the Least Religious Nations Can Tell Us About Contentment. New York: NYU Press.

\footnotetext{
TO CITE THIS ARTICLE:

Galen, L, Gore, R and Shults, FL. 2021. Modeling the Effects of Religious Belief and Affiliation on Prosociality. Secularism and Nonreligion, 10: 6, pp. 1-21. DOI: https://doi.org/10.5334/snr.128
}

Submitted: 07 August 2019 Accepted: 21 May 2021 Published: 17 June 2021

\section{COPYRIGHT:}

(c) 2021 The Author(s). This is an open-access article distributed under the terms of the Creative Commons Attribution 4.0 International License (CC-BY 4.0), which permits unrestricted use, distribution, and reproduction in any medium, provided the original author and source are credited. See http://creativecommons.org/licenses/by/4.0/.

Secularism and Nonreligion is a peer-reviewed open access journal published by Ubiquity Press.

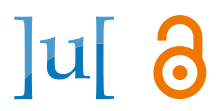

